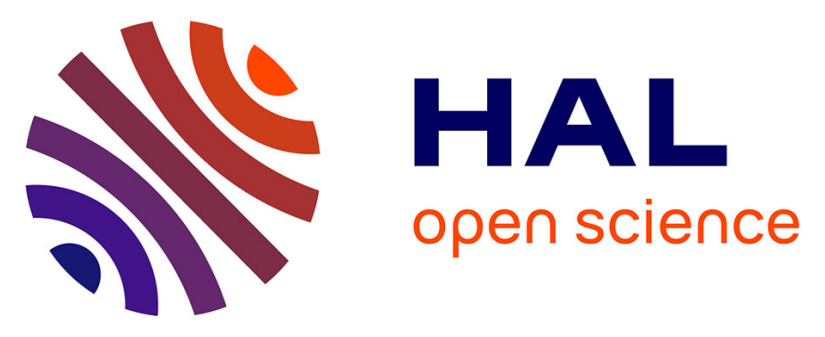

\title{
Betaine lipid and neutral lipid production under nitrogen or phosphorus limitation in the marine microalga Tisochrysis lutea (Haptophyta)
}

Bing Huang, Justine Marchand, Stanislas Thiriet-Rupert, Gregory Carrier, Bruno Saint-Jean, Ewa Lukomska, Brigitte Moreau, Annick Morant-Manceau, Gaël Bougaran, Virginie Mimouni

\section{To cite this version:}

Bing Huang, Justine Marchand, Stanislas Thiriet-Rupert, Gregory Carrier, Bruno Saint-Jean, et al.. Betaine lipid and neutral lipid production under nitrogen or phosphorus limitation in the marine microalga Tisochrysis lutea (Haptophyta). Algal Research - Biomass, Biofuels and Bioproducts, 2019, 40, pp.101506. 10.1016/j.algal.2019.101506 . hal-02495572

\section{HAL Id: hal-02495572 \\ https://hal.science/hal-02495572}

Submitted on 22 Oct 2021

HAL is a multi-disciplinary open access archive for the deposit and dissemination of scientific research documents, whether they are published or not. The documents may come from teaching and research institutions in France or abroad, or from public or private research centers.
L'archive ouverte pluridisciplinaire HAL, est destinée au dépôt et à la diffusion de documents scientifiques de niveau recherche, publiés ou non, émanant des établissements d'enseignement et de recherche français ou étrangers, des laboratoires publics ou privés.

\section{(ㄷ)(1) $\$$}

Distributed under a Creative Commons Attribution - NonCommerciall 4.0 International 
Betaine lipid and neutral lipid production under nitrogen or phosphorus limitation in the marine microalga Tisochrysis lutea (Haptophyta)

Bing Huang ${ }^{\mathrm{a}}$, Justine Marchand ${ }^{\mathrm{a}}$, Stanislas Thiriet-Rupert ${ }^{\mathrm{a}}$, Grégory Carrier ${ }^{\mathrm{b}}$, Bruno Saint-Jean $^{\mathrm{b}}$, Ewa Lukomska ${ }^{\mathrm{b}}$, Brigitte Moreau ${ }^{\mathrm{a}}$, Annick Morant-Manceau ${ }^{\mathrm{a} *}$, Gaël Bougaran $^{\mathrm{b} *}$, Virginie Mimouni $^{\mathrm{c} *}$

${ }^{a}$ Laboratoire Mer, Molécules, Santé (IUML - FR 3473 CNRS), UFR Sciences et Techniques, Le Mans Université, avenue Olivier Messiaen, 72085 Le Mans cedex 09, France

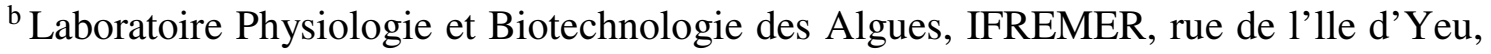
BP 21105, 44311 Nantes Cedex 03, France

${ }^{c}$ Laboratoire Mer, Molécules, Santé (IUML - FR 3473 CNRS), IUT Département Génie Biologique, Le Mans Université, 52 rue des Docteurs Calmette et Guérin, 53020 Laval cedex 9, France

* These authors contributed equally to this work

Corresponding author: virginie.mimouni@univ-lemans.fr

E-mail addresses: virginie.mimouni@univ-lemans.fr (V. Mimouni), gael.bougaran@ifremer.fr (G. Bougaran), annick.manceau@univ-lemans.fr (A. MorantManceau) 


\section{Abstract}

Nitrogen $(\mathrm{N})$ and phosphorus $(\mathrm{P})$ limitations induce neutral lipid accumulation and membrane lipid remodeling in the domesticated oleaginous microalga Tisochrysis lutea. This study compared growth, photosynthetic activity, biochemical and transcriptional responses of $T$. lutea throughout batch cultures under $\mathrm{N}$ or $\mathrm{P}$ limitation compared with non-limiting nutrient condition (NP). The results show that, under $\mathrm{N}$ limitation, the breakdown and re-use of cellular N-containing compounds contributed to carbohydrates and further triacylglycerol (TAG) accumulation, where the accumulation of docosahexaenoic acid (DHA) in neutral lipids might mainly be derived from the recycling of membrane polar lipids. Conversely, $\mathrm{P}$ limitation did not hinder the photosynthetic capacity; a higher efficiency of carbon fixation fueled the allocation of carbon fluxes to the reserves of carbohydrates and neutral lipids. These latter accumulated without massive degradation of essential cellular compounds. Betaine lipids constitute the major compounds of non-plastidial membranes in T. lutea. Given an extremely low constitutive phospholipid level, phospholipids might not be involved in the regulation of $\mathrm{P}$ storage. However, transfer of $\mathrm{P}$ from non-plastidial to chloroplast membranes might occur, keeping a stable lipid composition of thylakoid membranes and maintaining a relatively high photosynthetic capacity under $\mathrm{P}$ deprivation.

\section{Keywords:}

Tisochrysis lutea, phosphorus, nitrogen, lipid remodeling, betaine lipid, polyunsaturated fatty acid 


\section{Introduction}

Marine microalgae are unicellular photosynthetic eukaryotes that represent the largest phytoplankton group and play an important role in global processes such as $\mathrm{CO}_{2}$ fixation. They are responsible for approximately 50\% of Earth's primary production $[1,2]$ and form the basis of aquatic food networks. In the recent decades, the cultivation of microalgae has boomed around the world for use as feeds in aquaculture [3], biofuel feedstock [4], and especially for the production of a number of highly valuable compounds with potential applications in cosmetics, food-processing, and pharmaceutics [5-7]. Promising microalgal species are screened for commercial applications [8], and research is increasingly focused on the manipulation of algae by genetic and metabolic engineering [9] or the modulation of culture conditions [10] for specific purposes.

Microalgal biochemical composition, the quantity and quality of molecules of interest, can be affected by external cultivation conditions such as light, temperature, nutrient status, salinity stress etc. [11-15]. Different physicochemical parameters regulate cellular carbon storage and partitioning, although the mechanisms remain largely unknown. Nitrogen $(\mathrm{N})$ and phosphorus $(\mathrm{P})$ are the most limiting or co-limiting macro-elements in natural conditions [16]. The influence of these elements on the reorientation of carbon flux and cellular energy has been intensively studied [17-19]. Indeed, they are involved in the composition of essential molecules: $\mathrm{N}$ is mainly used to build proteins, amino acids, and nucleic acids, while $\mathrm{P}$ is mostly a constituent of nucleic acids and phospholipids [20]. $\mathrm{N}$ and $\mathrm{P}$ play different roles in cell metabolism and their scarcity causes different physiological responses [21,22] and alterations of the 
biochemical composition [20,23,24]. In microalgae, such changes particularly concern lipid content and profile [25-27].

$\mathrm{N}$ has been considered as the single most critical nutrient triggering neutral lipids (mainly as triacylglycerol, TAG) accumulation [28,29]. P limitation, however, promotes high intra- and interspecific variability in metabolic responses. It results in increased lipid content in Phaeodactylum tricornutum [25], Monodus subterraneus [30], Chaetoceros sp., and Diacronema lutheri, but decreased lipid content in Nannochloris atomus and Tetraselmis sp. [27]. Further analyses revealed a higher relative content of palmitic (C16:0) and oleic (C18:1n-9) acids and lower relative content of long chain omega-3 polyunsaturated fatty acids due to $\mathrm{P}$ deprivation [27]. In addition, to cope with P limitation, changes in lipid classes are often observed in microalgae, characterized by a substitution of phospholipids with glycolipids and/or betaine lipids [25,26,31-34]; conversely, in some other microalgae with intrinsically low phospholipid levels (e.g. Haptophyta), the betaine lipid content is independent of $\mathrm{P}$ availability $[34,35]$.

From the vast diversity of existing microalgae, we selected Tisochrysis lutea, formerly named Isochrysis affinis galbana (Tahiti strain), for our study. This golden brown microalga belongs to the Haptophyta phylum [36], has been widely used for many years as a feed in bivalve hatcheries [37,38], and has a promising future for the production of molecules of interest for healthcare. Indeed, this species is rich in long chain omega-3 polyunsaturated fatty acids, notably docosahexaenoic acid (DHA, C22:6n-3), whereas it lacks eicosapentaenoic acid (EPA, C20:5n-3) [39]. DHA is of special interest as a food additive with potential health benefits, such as the prevention and treatment of chronic diseases [40]. Studies have shown DHA to be important in bivalve larval performance due to its role in maintaining the structural and functional 
integrity of cell membranes [41-43]. Additionally, this species stores carbohydrates in the form of $\beta$-1,3-glucans known as chrysolaminarin [44]. The major neutral lipids in $T$. lutea have been identified as alkenones rather than TAG under $\mathrm{N}$ starvation and at stationary growth phase $[45,46]$. In this species, the main alkenones are C37 and C38 long-chain unsaturated methyl and ethyl ketones, stored in cytoplasmic lipid bodies [45].

The genome of T. lutea has recently been fully sequenced [47], making it the third species in the Haptophyta phylum to be sequenced. Many studies have investigated transcriptomic $[48,49]$, proteomic $[50,51]$ and biochemical changes [52] in this species under different $\mathrm{N}$ supplies. The impact of $\mathrm{N}$ availability on growth, carbon accumulation, and partitioning has also been modeled recently [53-55]. However, few studies have been devoted to evaluating the effects of $\mathrm{P}$ on metabolic reorientation, particularly lipid metabolism. The objective of the present study was to determine the effect of $\mathrm{P}$ on carbon partitioning, lipid classes, and fatty acid composition of T. lutea. For this purpose, the impact of $\mathrm{N}$ and $\mathrm{P}$ limitations were compared with non-limiting medium. Photosynthetic activity, residual $\mathrm{N}$ and $\mathrm{P}$ concentrations in the media, and different biochemical and transcriptional responses of $T$. lutea were measured throughout the culture period.

\section{Materials and methods}

\subsection{Growth conditions}

T. lutea CCAP 927/14 was obtained from the Culture Centre of Algae and Protozoa (Oban, Scotland). Axenic strain was maintained in batch culture in natural seawater (Saint Malo, France) enriched with Walne solution [56]. Starter cultures were grown in this same enriched seawater until the exponential growth phase was reached, 
cells were then harvested by centrifugation $(1000 \times \mathrm{g}, 15 \mathrm{~min})$ and transferred into natural seawater for 2 days. This 2-day period was necessary to lower the cellular $\mathrm{P}$ and $\mathrm{N}$ quotas and to minimize $\mathrm{N}$ and $\mathrm{P}$ inputs in the subsequent cultures. Cells were inoculated with an initial density of $10^{5}$ cells $\mathrm{mL}^{-1}$ in $1.5 \mathrm{~L}$-media prepared with seawater enriched with original Walne (control) or modified Walne (P-limited or Nlimited) solutions. The setting of nitrogen and phosphorus concentrations/ ratios in limited cultures was based on the previous study of Bougaran [57]. The non-modified or modified Walne solution resulted in nutrient concentrations of $1176 \mu \mathrm{M} \mathrm{NO}_{3}{ }^{-}$and 128 $\mu \mathrm{MPO}_{4}{ }^{3-}(\mathrm{N}: \mathrm{P}=9.18)$ in the control medium, $500 \mu \mathrm{M} \mathrm{NO}_{3}{ }^{-}$and $4 \mu \mathrm{M} \mathrm{PO}_{4}{ }^{3-}(\mathrm{N}: \mathrm{P}=$ $125)$ in the $\mathrm{P}$-limited medium, and $125 \mu \mathrm{M} \mathrm{NO}_{3}{ }^{-}$and $125 \mu \mathrm{M} \mathrm{PO}_{4}{ }^{3-},(\mathrm{N}: \mathrm{P}=1)$ in the $\mathrm{N}-$ limited medium. Growth in batch mode was conducted at $27 \pm 2^{\circ} \mathrm{C}$, under continuous fluorescent light (Osram 54W cool daylight) with a photon flux density of $300 \mu \mathrm{mol}$ photons $\mathrm{m}^{-2} \mathrm{~s}^{-1}$ and sterile-filtered air bubbling aeration (ambient $\mathrm{CO}_{2}$ ). Three biological replicates of each of the above treatments were studied. Cell density, volume, and growth rate were determined on samples fixed with Lugol (iodine solution) using light microscopy. Cell density was assessed using a Neubauer hemocytometer twice a day. Specific growth rate $(\mu)$ was calculated according to the equation: $\mu=\left(\ln \mathrm{N}_{\mathrm{t} 2}-\ln \mathrm{N}_{\mathrm{t} 1}\right) /$ (t2-t1), where $\mathrm{N}_{\mathrm{t} 2}$ and $\mathrm{N}_{\mathrm{t} 1}$ are the number of cells at two subsequent culture days ( $\mathrm{t} 2$ and t1). Cell volume was assessed with ZEN software (Carl Zeiss, Marly-le-Roi, France).

\subsection{Nutrient analyses}

Defined culture volumes containing about $30 \times 10^{6}$ cells were filtered on GF/C glass filters (Whatman, Fisher Scientific, Illkirch, France) and inorganic nutrients were measured in the filtrates. $\mathrm{NO}_{3}{ }^{-}$was determined by ultraviolet spectrophotometry [58], 
and $\mathrm{PO}_{4}{ }^{3-}$ was estimated by visible spectrophotometry using the methods described in [59]. Cells on filters were washed twice with $10 \mathrm{~mL} 0.516 \mathrm{M} \mathrm{NaCl}$, dried overnight at $60^{\circ} \mathrm{C}$, and stored at $-20^{\circ} \mathrm{C}$. Particulate carbon and nitrogen in cells were determined with a FLASH 2000 NC analyzer (Thermo Fisher Scientific, Villebon sur Yvette, France), and particulate phosphorus measured following wet oxidation [60].

\subsection{Chlorophyll $a$ fluorescence yield measurements}

Chlorophyll $a$ fluorescence yield measurements were performed at $27^{\circ} \mathrm{C}$ as described in [61], using a FMS1-modulated fluorimeter (Hansatech, Cergy, France). After a dark-adaptation period $(15 \mathrm{~min})$, the minimum $\mathrm{Chl}$ fluorescence yield $\left(\mathrm{F}_{0}\right)$ was recorded under a weak modulated light (less than $15 \mu$ mol photons $\mathrm{m}^{-2} \mathrm{~s}^{-1}$ ). Next, a saturation pulse (more than $1200 \mu \mathrm{mol}$ photons $\mathrm{m}^{-2} \mathrm{~s}^{-1}$ ) was applied to determine maximum fluorescence yield $\left(\mathrm{F}_{\mathrm{m}}\right)$. The maximum quantum yield $\left(\mathrm{F}_{\mathrm{v}} / \mathrm{F}_{\mathrm{m}}\right)$ was calculated according to the equation: $F_{\mathrm{v}} / \mathrm{F}_{\mathrm{m}}=\left(\mathrm{F}_{\mathrm{m}}-\mathrm{F}_{0}\right) / \mathrm{F}_{\mathrm{m}}$. PSII operating efficiency $\left(\Phi_{\mathrm{II}}\right)$, photochemical and non-photochemical quenching were determined following a $14 \mathrm{~min}$ non-saturating white actinic irradiation $\left(300 \mu \mathrm{mol}\right.$ photons $\left.\mathrm{m}^{-2} \mathrm{~s}^{-1}\right)$ according to $[61,62]$. For quenching components analysis, a higher actinic irradiance $\left(1000 \mu \mathrm{mol}\right.$ photons $\mathrm{m}^{-2}$ $\mathrm{s}^{-1}$ ) was applied, and dark relaxation of Chl fluorescence yield was recorded [61].

\subsection{Protein, carbohydrate, neutral lipid, and chlorophyll assays}

For proximate protein and carbohydrate assays, about $30 \times 10^{6}$ cells were harvested by centrifugation $(3000 \times \mathrm{g}, 10 \mathrm{~min})$, washed with $0.516 \mathrm{M} \mathrm{NaCl}$, resuspended in $2 \mathrm{~mL}$ ultrapure water and homogenized. The homogenate was centrifuged at $4^{\circ} \mathrm{C}, 16100 \mathrm{~g}$ for $20 \mathrm{~min}$, protein and carbohydrate dosages were then 
performed on the same cell lysate. Soluble protein content was quantified using the Bradford method [63], and soluble carbohydrate content by the phenol-sulfuric acid method [64].

Cellular neutral lipid accumulation was estimated by Nile red (Sigma-Aldrich, Saint-Quentin Fallavier, France) fluorescence. Briefly, $3 \mathrm{~mL}$ of cultures containing about $3 \times 10^{6}$ cells were stained directly with $3 \mu \mathrm{L}$ Nile red solution $\left(1 \mathrm{mg} \mathrm{mL}^{-1}\right.$ in acetone). The fluorescence was measured at excitation/emission wavelengths of 530/580 nm respectively (Perkin Elmer LS-55, Villebon sur Yvette, France).

The pigments $\mathrm{Chl} a, \mathrm{Chl} c$, and fucoxanthin were extracted from the cell pellet with $100 \%$ acetone and quantified spectrophotometrically (Perkin Elmer Lambda-25, Villebon sur Yvette, France) as described in [65].

\subsection{Lipid extraction and identification and fatty acid analysis}

For lipid analysis, about $300 \times 10^{6}$ cells were collected at days 2,4 , and 7 on a GF/C glass filter (Whatman, Fisher Scientific, Illkirch, France). Total lipids were extracted in a chloroform/methanol/0.28\% $\mathrm{NaCl}(1 / 2 / 0.2, \mathrm{v} / \mathrm{v} / \mathrm{v})$ mixture according to Bligh \& Dyer [66]. The solvent was then evaporated under partial vacuum using a rotary evaporator (Heidolph 94200, Fisher Scientific, Illkirch, France), and the dry extracts were stored in $2 \mathrm{~mL}$ pure chloroform at $-20^{\circ} \mathrm{C}$ under nitrogen. Total lipid content was quantified by carbonization [67] using triacylglycerol (TAG) as a standard (Sigma Aldrich, Saint-Quentin Fallavier, France).

Lipid classes were separated using thin layer chromatography (TLC) on $20 \times 20$ cm silica gel plates (Merck, Fontenay sous Bois, France). The silica plates were washed with isopropanol to eliminate impurities and then activated for $30 \mathrm{~min}$ at $120^{\circ} \mathrm{C}$ before 
utilization. Lipid extracts from about $7.5 \times 10^{6}$ cells were applied using a semi-automatic TLC Sampler (Camag Linomat V, Muttenz, Switzerland) and separated in TLC chambers. Three separation solvents were successively used: (1) methyl acetate/isopropanol/chloroform/methanol/0.25\% $\mathrm{KCl}$ (25/25/25/10/9, v/v/v/v/v), (2) methyl acetate/isopropanol/chloroform/methanol/0.25\% $\mathrm{KCl}(5 / 5 / 5 / 2 / 1$, v/v/v/v/v) and (3) hexane/diethyl ether/ glacial acetic acid (40/10/1, v/v/v). Lipids were visualized under UV light (366nm) after spraying with primuline (Sigma-Aldrich, Saint-Quentin Fallavier, France) [68]. Quantification was made with a digit image system (Versadoc 3000 Bio-Rad, Marnes-la-Coquette, France) combined with the Quantity One program (Bio-Rad, Hercules, USA) and a range of lipid standards. Visualization of phospholipids was carried out by spraying with Zinzadze reagent (Molybdenum Blue Spray, SigmaAldrich, Saint-Quentin Fallavier, France) [69]. All the lipid standards used for TLC analyses were obtained from Sigma-Aldrich (Saint-Quentin Fallavier, France) or Advanti Polar Lipids (Alabaster, USA).

Lipid fractions were separated using a column of $500 \mathrm{mg}$ silica gel 60 (normalphase, 0.063-0.200 mm, Merck, Fontenay sous Bois, France), preconditioned with pure chloroform. Pre-concentrated crude lipid samples were loaded onto the columns. Neutral lipids were eluted with $20 \mathrm{~mL}$ chloroform/acetone (9/1, v/v), glycolipids with 4 $\mathrm{mL}$ chloroform/methanol (5/2, v/v) and $6 \mathrm{~mL}$ acetone/methanol $(9 / 2, \mathrm{v} / \mathrm{v})$, and finally phospholipids and betaine lipids with $20 \mathrm{~mL}$ methanol/ $\mathrm{H}_{2} \mathrm{O}(9 / 1, \mathrm{v} / \mathrm{v})$. The fractions eluted were evaporated and dissolved in $2 \mathrm{~mL}$ pure chloroform for gas-chromatography analyses.

Fatty acid methyl esters (FAMEs) were obtained according to Slover \& Lanza [70]. FAMEs were analyzed with a Focus gas-chromatograph (Thermo Electron 
Corporation, Les Ulis, France) equipped with a capillary column CP Sil-88 $25 \mathrm{~m} \times 0.25$ mm (Varian, Les Ulis, France). Nitrogen was used as the mobile phase with a constant flow rate of $1 \mathrm{~mL} / \mathrm{min}$. Injection was performed in the split mode at $250^{\circ} \mathrm{C}$. The analyses were carried out from $120^{\circ} \mathrm{C}$ to $220^{\circ} \mathrm{C}: 120^{\circ} \mathrm{C}$ for $4 \mathrm{~min}, 120-220^{\circ} \mathrm{C}$ with $6^{\circ} \mathrm{C} / \mathrm{min}$ and held at $220^{\circ} \mathrm{C}$ for $5 \mathrm{~min}$. FAMEs were detected with a flame-ionization detector, analyzed with the Azur V4 program (Datlys, Les Ulis, France), identified from authentic FAME standards (Sigma-Aldrich, Saint-Quentin Fallavier, France), and expressed as molar percent of total fatty acids.

\section{6 mRNA quantification}

About $100 \times 10^{6}$ cells were harvested at days 2,4 , and 7 by vacuum filtration on a precombusted $\left(150^{\circ} \mathrm{C}, 6 \mathrm{~h}\right) 47 \mathrm{~mm} \mathrm{GF} / \mathrm{C}$ glass filter (Whatman, Fisher Scientific, Illkirch, France), then immediately frozen in liquid nitrogen and stored at $-80^{\circ} \mathrm{C}$. Total RNA was extracted using the Spectrum Total RNA kit (Sigma-Aldrich, Saint-Quentin Fallavier, France) protocol with on-column DNase digestion using DNase I (SigmaAldrich, Saint-Quentin Fallavier, France). The quality and concentration of the eluted RNA were determined by UV absorbance at 260 and $280 \mathrm{~nm}$ (Nanodrop 2000c, Thermo Fisher Scientific, Villebon sur Yvette, France). A total of $1 \mu \mathrm{g}$ RNA was reverse transcribed, following the M-MLV Reverse Transcriptase (Promega, Charbonnières les Bains, France) protocol. cDNA samples were diluted 1/10 before quantitative real-time PCR (qRT-PCR) analysis.

Reactions were performed on a StepOnePlus Real-Time PCR system (Applied Biosystems, Villebon sur Yvette, France), with the standard cycling program composed of a pre-incubation for $2 \mathrm{~min}$ at $95^{\circ} \mathrm{C}$ followed by 40 cycles of amplification: $95^{\circ} \mathrm{C}$ for 
$15 \mathrm{~s}, 60^{\circ} \mathrm{C}$ for $1 \mathrm{~min}$, and a final melting analysis $\left(60-95^{\circ} \mathrm{C},+0.3^{\circ} \mathrm{C} / 30 \mathrm{~s}\right)$. The threshold cycle $\left(\mathrm{C}_{\mathrm{t}}\right)$ value and primer efficiency for individual reactions was determined by analysis of raw fluorescence data using PCR Miner software [71].

Based on KEGG (Kyoto Encyclopedia of Genes and Genomes) pathway assignments, 10 enzymes involved in TAG and membrane lipid biosynthetic pathways were selected and the corresponding genes/isogenes were searched for with the proteome data of the diatom P. tricornutum [72] and the Haptophyta Emiliana huxleyi [73] (available in JGI http://www.jgi.doe.gov/) by BLAST analysis [74] against a database of $T$. lutea available at the IFREMER-Nantes laboratory [47]. Ten housekeeping gene (HKG) candidates were studied using Bestkeeper Software [75]: TBP (TATA box binding protein), Ub (ubiquitin), Hist (histone), Actin3, Actin4, TubA (tubulin $\alpha$ ), TubB (tubulin $\beta$ ), EF1a (elongation factor 1 $\alpha$ ), GAPDH1 (glyceraldehyde 3phosphate dehydrogenase), and GAPDH2. The most stable (displaying weak $\mathrm{C}_{\mathrm{t}}$ standard deviation and high pairwise correlation) were selected as the endogenous reference to accurately normalize the target gene transcription. The relative mRNA expression (RE) of a target gene was calculated using the $\Delta \Delta \mathrm{C}_{\mathrm{t}}$ method [76], calibrated to the day-2 control cells (exponential phase). The primer sets used are summarized in Supplementary Table S1.

\section{7 $\quad$ Statistical analysis}

Means comparisons were tested using a one-way repeated measures ANOVA followed by a Fisher's LSD post-hoc test. In all cases, a $\mathrm{p}$ value $\leq 0.05$ was considered to be statistically significant. Unless otherwise specified, the SIGMAPLOT software 
package was used for all statistical calculations. All the results were expressed as means \pm standard errors.

Membrane lipid and fatty acid (FA) data were analyzed with a similarity percentage analysis (SIMPER), performed on the relative percentage data to demonstrate the dissimilarity in membrane lipid and FA composition. SIMPER identified the compounds that contributed the most to the variance between tested conditions. The membrane lipids and FAs, which together contributed up to $>80 \%$ of the dissimilarities, were selected to identify the differences between culture conditions. Data on the relative percentage were logarithmically $(\log [\mathrm{x}+1])$ transformed and converted into a Bray-Curtis similarity matrix. A one-way analysis of similarities (ANOSIM) was used to statistically test the overall difference by calculating a global $\mathrm{R}$ statistic that weights the differences between groups of sampling units. An R value close to 1 indicates high separation of the clusters, while a value of 0 represents the null hypothesis [77]. SIMPER and ANOSIM analyses were performed using R (Community Ecology Package, version 2.4-6) [78].

\section{Results and discussion}

\subsection{Effects of $\mathbf{N}$ and $P$ limitations on growth}

T. lutea cells were cultured for 9 days in batch mode. The N-limited (N-) and Plimited (P-) cultures showed similar growth curves compared with control (NP) cultures during exponential growth, as the specific growth rate reached its maximum $\left(1.8-1.9 \mathrm{~d}^{-1}\right)$ within $32 \mathrm{~h}$ without any significant difference (Fig. 1A-D). The N-limited cells entered into stationary phase on day $3\left(\mu<0.2 \mathrm{~d}^{-1}\right)$, after about $24 \mathrm{~h}$ of $\mathrm{N}$ deprivation $\left(\mathrm{NO}_{3}{ }^{-}\right.$ concentration lower than detection limit), with a cell density of $2.3 \times 10^{6}$ cells $\mathrm{mL}^{-1}$ (Fig. 
1B). The P-limited cells entered into stationary phase on day $4\left(\mu<0.2 \mathrm{~d}^{-1}\right)$, after about $48 \mathrm{~h}$ of $\mathrm{P}$ deprivation $\left(\mathrm{PO}_{4}{ }^{3-}\right.$ concentration lower than detection limit), with a cell density of $3.8 \times 10^{6}$ cells $\mathrm{mL}^{-1}$ (Fig. 1C). According to the growth rate evolution, days 2 , 4, and 7 in the nutrient-limited cultures were chosen, for convenience, to represent the exponential growth phase, early stationary phase, and late stationary phase, respectively, for the subsequent experiments. It was noted that control cells reached early stationary phase on day 7 (Fig. 1D).

Under N-limited conditions, no significant cell volume change was observed during the cultures (Fig. 2). $\mathrm{N}$ limitation slightly increased the cellular $\mathrm{C}$ content when cell division was slowed down, however this accumulation only lasted during the early stationary phase. Cellular $\mathrm{C}$ content subsequently remained constant from day 4 onward (Fig. 3A), and the $\mathrm{N}$ quota (N/C) remained very low (Fig. 3B). N limitation seemed to decline the P quota (P/C), which was a little lower than in the control cells (Fig. 3C). This difference might be due to competition for energy use between active $\mathrm{N}$ - and Puptake systems $[53,79]$. Nonetheless, the $\mathrm{P}$ quota remained stable at a high level during the stationary phase (Fig. 3C).

In stark contrast, P deficiency caused enlargement of cell size (Fig. 2). Mean cell volume had almost doubled by day 7 compared with day-4 cells (from 66 to $112 \mu \mathrm{m}^{3}$ ). This enlarged cell size may be related to perturbation in the progression of the cell-cycle [80]. Similar results were observed in several other algae $[32,33,81-83]$, some of which were shown to be arrested at the G1 phase due to disabling of DNA duplication or protein phosphorylation [81-83]. This enlargement of cell size during P scarcity was accompanied by high cellular $\mathrm{C}$ accumulation (Fig. 3A). The cellular $\mathrm{C}$ content increased gradually at stationary phase and was about twice that of control cells on day 
7. A continuous $\mathrm{N}$ uptake into cells was also observed at stationary phase until $\mathrm{N}$ deprivation. However, the $\mathrm{N}$ quota was highly reduced (Fig. 3B), as previously described by a modeling approach [53], suggesting that $\mathrm{N}$ uptake or assimilation rate was also decreased. No significant difference of the $\mathrm{N}$ quota was observed between $\mathrm{N}$ and P-limited cells at late stationary phase (Fig. 3B). The cellular P quota reached its minimum from day 4 onward (Fig. 3C).

\subsection{Effects of $\mathrm{N}$ and $\mathrm{P}$ limitations on photosynthetic activity}

Chl $a$ and Chl $c$ contents were strongly reduced in N-limited cultures during stationary phase (Fig. 4A, B). As chlorophylls are mainly involved in light harvesting complexes and reaction centers [84], such a decline directly impaired the photosynthetic efficiency and cellular productivity. These results are in good agreement with a previous proteomic study [50], where the authors pointed out a decrease of proteins involved in the pigment biosynthetic process and carbon fixation under $\mathrm{N}$ deprivation. Otherwise, the chlorophyll content was less affected in P-limited cultures, but it still decreased gradually at stationary phase, which might be due to the lack of ATP and NADPH needed for chlorophyll synthesis [85] or to the constraint on $\mathrm{N}$ quota.

Fucoxanthin, as the major carotenoid in T. lutea [86], not only acts as an accessory light-harvesting pigment, but also plays a role as direct quencher of $\mathrm{Chl} a$ triplet $[87,88]$. In contrast to chlorophyll, fucoxanthin content was much less affected in both nutrient-limited conditions (Fig. 4C). A gradual increase of fucoxanthin-tochlorophyll ratio was observed, especially under $\mathrm{N}$ starvation (data not shown), thus preventing and lowering potential oxidative damage to the photosynthetic apparatus. 
The maximum quantum yield of PSII photochemistry $\left(\mathrm{F}_{\mathrm{v}} / \mathrm{F}_{\mathrm{m}}\right)$ dropped quickly in N-limited cultures from early stationary phase onward (Fig. 5A), indicating very stressful conditions and a reduced photosynthetic capacity of PSII reaction centers. In contrast, $\mathrm{F}_{\mathrm{v}} / \mathrm{F}_{\mathrm{m}}$ remained nearly unaltered in P-limited cultures compared with control cultures, indicating that P deprivation had no severe effect on PSII in T. lutea. Similarly, PSII operating efficiency $\left(\Phi_{\text {II }}\right.$ (Fig. 5B) declined more quickly in N-limited cultures during early stationary phase, indicating a reduced flux of electrons through the electron-transport chain of PSII. This result is consistent with the lower photochemical quenching (qP) value (Fig. 5C), suggesting that most of the PSII reaction centers were closed. In P-limited cultures, $\Phi_{\text {II }}$ dropped at late stationary phase without a significant decrease of $\mathrm{qP}$ value (Fig. 5B, C), indicating that another scenario might take place when cells were exposed to severe P starvation. This $\Phi_{\text {II }}$ decline might be due to the delay of electron transfer modulated by the rate of $\mathrm{CO}_{2}$ fixation $[89,90]$, which might be strongly reduced due to the depletion of phosphorylated intermediates $[91,92]$.

Non-photochemical quenching (NPQ) is an important mechanism that allows dissipation of excess light energy as heat, thus maintaining the balance between the photon energy absorbed and energy utilized [93]. In the present study, NPQ started to increase in both $\mathrm{N}$ - and P-limited cultures from stationary phase onward (Fig. 5D). However, values remained very low compared with those previously obtained in diatoms. Similar results have been reported in the closely related species Isochrysis galbana [94], and the authors of this previous study indicated that NPQ is not strong enough to dissipate the excess excitation energy, so other mechanisms, like cyclic electron flow, might play a physiologically important role in countering photo-damage [94]. 
To gain further insight into the non-photochemical quenching, complementary measurements were made during the relaxation period. As reported by [61,95], three individual components of non-photochemical quenching ( $\mathrm{qN})$ of variable $\mathrm{Chl}$ fluorescence: $\mathrm{qN}_{\mathrm{f}}$ (s time-scale), $\mathrm{qN}_{\mathrm{i}}$ (min time-scale), and $\mathrm{qN}_{\mathrm{s}}$ (h time-scale) were determined (Fig. 5E). $\mathrm{qN}_{\mathrm{f}}$ is considered to be related to a fast conformation change in pigment-protein complexes of the PSII antenna at the start of the relaxation process [61]. Here, the proportion of $\mathrm{qN}_{\mathrm{f}}$ was more significantly reduced in $\mathrm{N}$-limited cultures than in P-limited cultures, suggesting a modification at the thylakoid membrane level. A significant increase of $\mathrm{qN}_{\mathrm{s}}$ was observed in both $\mathrm{N}$ - and P-limited cultures, which might be related to an enhanced photo-inhibition of PSII. The proportion of $\mathrm{qN}_{\mathrm{i}}$, however, was greatly reduced under limiting conditions. $\mathrm{qN}_{\mathrm{i}}$ relies on $\Delta \mathrm{pH}$ relaxation and xanthophyll deepoxidation through the xanthophyll cycle [61]. A lower $\mathrm{qN}_{\mathrm{i}}$ in both $\mathrm{N}$ - and P-limited cultures suggests a weak activation of the xanthophyll cycle, confirming the results obtained with NPQ.

Different acclimation mechanisms are therefore employed in T. lutea according to the type of nutrient limitation. Under $\mathrm{N}$-limited stress, the chlorophyll content decreases and the photosynthetic capacity of the PSII reaction centers are limited, reducing the capture of light energy and inorganic carbon fixation. In contrast, under Plimited stress, the photosynthetic machinery seems to be less affected, ensuring an increased cellular $\mathrm{C}$ accumulation during the stationary phase. Furthermore, NPQ might not be a sufficient mechanism to reduce the excess energy in T. lutea, and enhanced alternative electron flows as well as high fucoxanthin-to-chlorophyll ratio could act to prevent the formation of reactive oxygen species (ROS). 


\subsection{Effects of $\mathrm{N}$ and $\mathrm{P}$ limitations on carbon partitioning}

Cellular soluble protein, carbohydrate, and neutral lipid contents were measured throughout the cultures (Fig. 6A-C). Because cellular $\mathrm{C}$ content and cell volume varied with the type of nutrient limitation, as observed in [96], carbon partitioning between the different metabolites based on cellular units could be biased. Results were thus expressed on cellular C quota basis, avoiding cell volume changes issues [97].

Under N-limited conditions, the soluble protein content per unit cell $\mathrm{C}$ decreased from late exponential growth phase onward (Fig. 6A). The lowest protein value was recorded at late stationary phase. This reduced protein content has also been reported in earlier studies $[12,52,98]$, which might be related to a lower availability of $\mathrm{N}$ for protein synthesis and an accelerated degradation of amino acids [50]. The products of amino acid decarboxylation could provide both the reducing power (NADH) and the precursor of acetyl-CoA for further fatty acid biosynthesis [99]. Carbohydrates and neutral lipids are generally considered to be the main carbon reserves. The soluble carbohydrate (mainly chrysolaminarin) content per unit cell $\mathrm{C}$ sharply increased during $\mathrm{N}$ limitation (Fig. 6B), suggesting an enhanced carbohydrate accumulation, as previously reported in $[12,52,98]$. These previous studies revealed a negative linear correlation between $\mathrm{N}$ availability and carbohydrate content in $T$. lutea [51,55]. The increase of cellular carbohydrate content led to carbon accumulation and reached its highest value at the early stationary phase (Fig. 3A), as already observed in the same species by Garnier et al. [51]. Then, $\mathrm{N}$ starvation slightly reduced carbohydrate content, stopping cellular carbon accumulation as mentioned above, but a steady neutral lipid accumulation was simultaneously observed (Fig. 6C), suggesting that carbohydrates were used as primary energy storage and neutral lipids as secondary storage [52]. Carbohydrates could be 
partially used and converted into neutral lipids under $\mathrm{N}$ starvation, as Garnier et al. [50] pointed out that lipid accumulation in T. lutea could be closely related to carbohydrate metabolism. Our results are in accordance with the dynamic model of accumulation of storage carbohydrates and lipids during $\mathrm{N}$ depletion proposed in [54]. Because this microalga produces only a small amount of triacylglycerols (TAG) $[13,45,46]$, the increased neutral lipid content might mainly due to the accumulation of alkenones in $\mathrm{N}$ starved culture [52]. Overall, under $\mathrm{N}$ limitation conditions, carbohydrates rather than storage lipids were the main pool of carbon allocation in T. lutea [23,51].

P starvation did not induce protein degradation, but lower protein content per unit cell $\mathrm{C}$ indicates that $\mathrm{C}$ partitioning toward proteins was gradually inhibited (Fig. 6A). This inhibition might be related to an overall global constraint on RNA and ATP synthesis [33,100]. Carbohydrate accumulation (Fig. 6B) occurred during late exponential phase and was then steady compared with N-limited or NP cultures, while neutral lipid accumulation (Fig. 6C) accelerated during stationary phase. Carbohydrate and lipid syntheses could compete for the use of precursors [101]. We noticed that carbohydrate content per unit cell $\mathrm{C}$ was lower than in $\mathrm{N}$-limited cells, suggesting that under P-limitation, energy metabolism might be promoted at the expense of carbohydrate accumulation [102]. As a result, more fixed carbon might be directly engaged in energy metabolism, which mediates the formation of acetyl-CoA and NADH, and then toward fatty acid biosynthesis. In agreement with previous studies [23], neutral lipid accumulation is promoted under P starvation. Interestingly, the curves of neutral lipid content per $\mathrm{C}$ show similar trend under $\mathrm{N}$ and P-limited conditions, suggesting that neutral lipid accumulation could occur as part of a "pushed" scenario in order to 
consume excess $\mathrm{C}$ and reductive power when the relative growth rate is weak or null [103].

\subsection{Effects of $\mathrm{N}$ and $\mathrm{P}$ limitations on lipid metabolism}

The total lipid : C ratio (Fig. 6D) remained relatively constant under the different culture conditions, as reported in previous studies [12,104]. Despite the increase of neutral lipids (Fig.6C), the partitioning of carbon to membrane polar lipids was reduced due to the stopping of cell division. Neutral lipids are considered to be the predominant component of total lipids under conditions of limitation [105], this enhanced neutral lipid accumulation in T. lutea and other microalgae involves a combination of de novo biosynthesis of lipids and glycerolipid recycling from membrane lipids to lipid bodies $[25,33,51,106,107]$, while membrane polar lipids undergo broad remodeling depending on the nutrient limitation $[25,30,32-35,108]$. In the present study, we analyzed lipid profiles using multiple analytical techniques to examine the different lipid remodeling modes in T. lutea in response to $\mathrm{N}$ and $\mathrm{P}$ deprivation.

Under N-limited conditions, neither the Kennedy pathway $[51,109,110]$ (including the four major enzymes: glycerol-3-phosphate-O-acyltransferase (GPAT), 1acyl-sn-glycerol-3-phosphate acyltransferase (AGPAT), phosphatidic acid phosphatase (PAP), and diacylglycerol O-acyltransferase (DGAT)) nor the acyl-editing mechanisms [51,110,111] (including phospholipid-diacylglycerol acyltransferase (PDAT)), the two main TAG biosynthesis pathways, were induced (Fig. 7A). In addition, we recorded a down-regulation of the gene encoding AGPAT, which was in accordance with a proteomic analysis reported in a previous study [51]. These authors observed a conversion of membrane lipids to storage lipids after changes of $\mathrm{N}$ availability in $T$. 
lutea, without activation of de novo TAG synthesis, suggesting that TAGs are mainly synthesized from membrane lipid hydrolysis [51]. Our results suggest a weak TAG accumulation during $\mathrm{N}$ limitation, whereas alkenones might be the major neutral lipid storage in N-limited culture as mentioned earlier $[45,46]$. Conversely, in P-limited cultures, TAG assembly increased at the transcript level (Fig. 7B). Both the Kennedy pathway and the acyl-editing mechanisms were slightly activated and further upregulated at late stationary phase, favoring TAG production. These up-regulations were consistent with the elevated neutral lipid per unit cell $\mathrm{C}$ measured at the end of the culture (Fig. 6C).

Five different glycolipids were separated by TLC, as also reported by Marchetti et al. [112], with sulfoquinovosyldiacylglycerol (SQDG), monogalactosyldiacylglycerol (MGDG), and digalactosyl-diacylglycerol (DGDG) as the main compounds. However, the superposition of spots and imperfect alignment with standards resulted in an imprecise identification of phospholipids and betaine lipids. With our current method, we did not detect phosphatidylcholine (PC). Phosphatidylinositol (PI) and phosphatidylglycerol (PG) were the major phospholipids identified in $T$. lutea in this study. Five different compounds of betaine lipids were also found, including diacylglycerol-3-carboxymethyl-choline (DGCC), diacylglycerol hydroxymethylN,N,N-trimethyl- $\beta$-alanine (DGTA), diacylglycerol trimethylhomoserine (DGTS), and two putative betaine lipids: BLx1 and BLx2.

Thylakoid membranes are composed of SQDG, DGDG, MGDG, and PG [113]. SQDG appears to be the most abundant glycolipid in T. lutea (Fig. 8A). It strongly inhibits the deepoxidation of diadinoxanthin [114,115], which may be related to the weak NPQ value mentioned above (Fig. 5E). N limitation induced a reorganization of 
thylakoid membranes (10\% dissimilarity on day 4 without any difference, $\mathrm{R}=0, \mathrm{p}=$ 0.007 , and $22 \%$ dissimilarity on day 7 with a strong overall difference, $\mathrm{R}=0.9259, \mathrm{p}=$ 0.001, compared with day-2 cells) (Fig. 8A). This reorganization is mainly driven by the reduction of SQDG (contributing up to $50 \%$ of the total dissimilarity), while DGDG, MGDG, and PG contents were relatively less affected (data not shown). SQDG is an anionic glycolipid with a negative charge on the head group that plays an important role in chloroplast structure and function [116,117]. The deficiency of SQDG could decrease the efficiency of electron donation and impair PSII activity [118], as shown in Fig. 5B.

Following P deprivation, thylakoid membrane composition was less affected (5\% dissimilarity on day 4 without any difference, $\mathrm{R}=-0.222, \mathrm{p}=0.009$, and $7 \%$ dissimilarity on day 7 with a very weak overall difference, $\mathrm{R}=0.2593, \mathrm{p}=0.002$, compared with day-2 cells) (Fig. 8A). Maintenance of lipid composition in thylakoid membranes makes it possible to sustain a strong photochemical capacity under Plimiting conditions (Fig. 5A). The up-regulation of the predicted genes encoding SQDG synthase 2 (SQD2), MGDG synthase (MGD1) and phosphatidate cytidylyltransferases (CDS) (Fig. 7B) might play an important role in keeping thylakoid membrane stable under $\mathrm{P}$ shortage in T. lutea despite the fact that partitioning of carbon to plastidial membrane lipids was reduced (data not shown).

Betaine lipids constitute the major compounds of non-plastidial membranes in $T$. lutea, with DGCC being the main lipid class, accounting for $24-34 \%$ of the total extraplastidial lipids in all experimental conditions, while phospholipids remained at a very low level (Fig. 8B). Under $\mathrm{N}$ limitation, the non-plastidial membrane composition showed $16 \%$ dissimilarity on day 4 without any difference $(R=-0.1481, p=0.007)$ and $17 \%$ dissimilarity on day 7 with a moderate overall difference $(\mathrm{R}=0.4815, \mathrm{p}=0.001)$, 
compared with day-2 cells. This increase in overall difference was mainly driven by the increase in DGTS (contributing up to $40 \%$ of the total dissimilarity) (Fig. 8B). In Chlamydomonas as well as in P. tricornutum, DGTS is thought to be a major source that mediates the flux of fatty acids toward TAG synthesis $[119,120]$. Generally, the proportion of betaine lipids and PI showed no differences compared with NP cultures (Fig. 8B).

As expected, P limitation greatly reduced PI content. The non-plastidial membrane composition showed $15 \%$ dissimilarity on day 4 with a moderate overall difference, $\mathrm{R}=0.4815, \mathrm{p}=0.001$, and $18 \%$ dissimilarity on day 7 with a strong overall difference, $\mathrm{R}=0.8148, \mathrm{p}=0.001$, compared with day-2 cells (Fig. 8B). As observed in $\mathrm{N}$-limited cultures, this increased overall difference was also due to the increase in the proportion of DGTS, contributing $38 \%$ of the total dissimilarity on day 4 and $>40 \%$ on day 7, whereas the decrease in PI only contributed $23 \%$ of the dissimilarity on day 4 and $21 \%$ on day 7 , respectively.

Further analyses indicated that $\mathrm{P}$ limitation did not disturb total phospholipid content per cell in T. lutea (data not shown). As mentioned previously, the decrease of PI in the extraplastidial membrane is compensated by the increase of PG in thylakoid membranes, suggesting a transfer of $\mathrm{P}$ from non-plastidial membranes to chloroplasts that would maintain a stable lipid composition of thylakoid membranes and a relatively high photosynthetic capacity under P deprivation. Our results confirm the hypothesis of Cañavate et al. [34,35] who concluded that, given the extremely low levels of constitutive phospholipids, they might not be involved in the regulation of $\mathrm{P}$ storage. Such low phospholipid levels have also been reported in other Haptophyta such as $I$. galbana (Parke), Diacronema vlkianum and D. lutheri $[34,108,121]$. In these species, 
the lower $\mathrm{P}$ requirement for lipid metabolism could be an optimized mechanism of evolutionary adaptation to $\mathrm{P}$-limitation, allowing increased $\mathrm{P}$ allocation to other essential physiological functions $[18,122]$.

In addition, one of the putative betaine lipid synthesis enzymes (BTA1) was upregulated at the transcriptional level (2.9 and 3.2-fold on day 4 and 7, respectively) under P-limited conditions (Fig. 7B). This up-regulation might be related to the enlargement of cell size (Fig. 2), which led to a significant increase in betaine lipid content per cell, despite the fact that the betaine lipid (DGCC, DGTA) content per unit cell C remained constant or reduced (data not shown).

The fatty acid (FA) composition of each major lipid fraction in T. lutea on day 4 is given in Fig. 9. The major FA of neutral lipids were oleic (C18:1n-9), palmitic (C16:0), myristic (C14:0), and stearidonic (C18:4n-3) acids, accounting for $75-85 \%$ of total FA in neutral lipids under all experimental conditions (Fig. 9A). The main changes in neutral lipids of the FA profile concerned C16:0, C18:1n-9, docosahexaenoic (DHA, C22:6n-3), linoleic (C18:2n-6), C18:4n-3, and $\alpha$-linolenic (C18:3n-3) acids (12\% dissimilarity under both $\mathrm{N}$ - and P-limited cultures compared with NP culture). The FA composition of neutral lipids showed little overall difference under $\mathrm{N}$ limitation $(\mathrm{R}=$ $0.1852, p=0.002$ ), despite the DHA proportion, which significantly increased from $6 \%$ to $10 \%$. This accumulation of DHA in the neutral lipid fraction might have mainly arisen from the recycling of membrane polar lipids as mentioned above, whereas de novo TAG synthesis remained weak. During P limitation, a slight overall difference of FA profile in neutral lipids was noted $(R=0.3704, p=0.002)$, where the saturated fatty acid C16:0 was significantly increased. C16:0 is the newly synthesized FA in chloroplasts $[123,124]$, its increase in neutral lipids suggested an activation of de novo 
FA synthesis in T. lutea under P limitation. Moreover, this newly synthesized FA could be directly used for TAG assembly.

The major FAs of glycolipids were C18:1n-9, C16:0, C14:0 and C18:4n-3, accounting for $74-82 \%$ under all experimental conditions (Fig. 9B). Despite variations of chloroplast glycolipid content under $\mathrm{N}$ and $\mathrm{P}$ limitations, their FA composition appeared to be unaltered ( $\mathrm{R}=0.1481, \mathrm{p}=0.003$ in $\mathrm{N}-; \mathrm{R}=-0.1852, \mathrm{p}=0.009$ in $\mathrm{P}-$ ). This stability could contribute to maintaining efficient photosynthetic activity.

In phospho- and betaine lipids, the major FAs were C18:1n-9, DHA and C16:0, which accounted for $75-90 \%$ under all experimental conditions (Fig. 9C). DHA is mainly associated with phospholipids and betaine lipids in T. lutea. A strong overall difference was observed under $\mathrm{N}$ limitation $(\mathrm{R}=0.963, \mathrm{p}=0.001)$, the main changes in FA profile were associated with C18:1n-9 increase and concomitant DHA, C16:0, C14:0 and palmitoleic (C16:1n-7) acids decrease (31\% dissimilarity compared with NP culture). A high C18:1n-9 proportion suggests a de novo FA synthesis outside the chloroplast [124,125], where betaine lipids or phospholipids could act as the first acceptor of de novo-formed FAs [121]. The increase of C18:1n-9 proportion under Nlimited conditions might be related to the breakdown and re-use of cellular N-containing compounds contributing to lipid synthesis. However, the proportion of DHA dramatically dropped under $\mathrm{N}$ limitation. Previous studies have demonstrated that the amount of long-chain FAs decreases under $\mathrm{N}$ limitation $[13,23,126]$. DHA and other C20-22 FAs that decreased in the phospho- and betaine lipid fraction might be partly incorporated into TAG synthesis, as mentioned earlier, or be the result of a weaker elongation. In contrast, the FA composition of phospho- and betaine lipids showed barely any difference under $\mathrm{P}$ limitation $(\mathrm{R}=-0.2593, \mathrm{p}=0.009)$, with a high DHA 
proportion of 35\%. Given the increase of betaine lipid content per cell, DHA level per cell increased $\sim 1.9$ times compared with NP cultures (data not shown). Considering the importance of DHA in human health [40] and in bivalve hatcheries [41-43], T. lutea appears to be a good candidate for biotechnological applications.

\section{Conclusions}

This work focused on the responses of the domesticated oleaginous microalga $T$. lutea to nutrient limitation. It compared the impact of $\mathrm{N}$ and $\mathrm{P}$ limitations on growth, photosynthesis, metabolic reorientation, and especially lipid profile remodeling, revealing different acclimation strategies. Under $\mathrm{N}$ limitation, chlorophyll content decreased and photosynthetic capacity of PSII reaction centers was partially inhibited, reducing capture of light energy and inorganic carbon fixation. The breakdown and inter-conversion of cellular N-containing compounds contributed to carbohydrates and further TAG accumulation, carbohydrates being the major pool of carbon allocation. On the contrary, under P limitation, neither light harvesting complexes nor PSII reaction centers seemed to be hindered, ensuring an increased $\mathrm{C}$ accumulation as well as an enlargement of cell size during stationary phase. This enhanced $\mathrm{C}$ accumulation ultimately fueled allocation of carbon fluxes to carbohydrates and TAG, without massive degradation of essential cellular compounds. Moreover, more efficient transcriptional up-regulation favors TAG synthesis during P deprivation.

Given the extremely low constitutive phospholipid level in $T$. lutea, phospholipids might not be involved in the regulation of P storage. However, transfer of P from non-plastidial to chloroplast membranes might occur, keeping a stable lipid composition of thylakoid membranes and maintaining a relatively high photosynthetic 
capacity under P deprivation. The proportion of the betaine lipid DGTS in non-plastidial membranes tended to increased under both nutrient limitations. Nevertheless, DGTS might not be a substitute for phospholipid, but as a major source mediating the flux of fatty acids toward TAG.

DHA is mainly associated with phospholipids and betaine lipids in T. lutea. Under $\mathrm{N}$ limitation, accumulation of DHA in neutral lipids was observed, which might mainly be derived from the recycling of membrane polar lipids. Otherwise, a high DHA proportion in the phospho- and betaine lipid fraction was maintained under P limitation. This source of omega-3 FA is of great interest for human health and bivalve hatcheries.

The present study provides the overall lipid profile of $T$. lutea at different growth phases and under $\mathrm{N}$ and $\mathrm{P}$ limitations. Further research is needed to distinguish additional lipid classes and to determine their FA composition in order to improve understanding of de novo FA synthesis and the trafficking of FA between the different compartments.

\section{Acknowledgements}

This work was funded by the region Pays de la Loire (France) through the Atlantic MicroAlgae contract. The authors thank Adrien Cadoudal and Léa Mustière, the Master's students, for their technical assistance and Helen McCombie-Boudry for correcting the English language.

\section{Author's contributions}

Annick Manceau, Gael Bougaran and Virginie Mimouni contributed equally to this work. They made substantial contributions to conception and design of the study, to 
analysis and interpretation of data, to critical revision of the article for important intellectuel content. Gael Bougaran contributed also in obtaining the funding. Bing Huang contributed to analysis and interpretation of data, drafting of the article, statistical expertise, collection and assembly of data. Justine Marchand, Grégory Carrier, Bruno Saint-Jean and Stanislas Thiriet-Rupert contributed to genome analysis and interpretation of data. Ewa Lukomska and Brigitte Moreau provided technical support for elemental analysis and qPCR respectively.

\section{Conflict of interest statement}

The authors declare that this manuscript has not any potential financial or other interests that could be perceived to influence the outcomes of the research.

\section{Statement of informed consent, human/animal rights}

No conflicts, informed consent, human or animal rights applicable. 


\section{Figure captions}

Fig. 1. Growth of T. lutea under control (NP), N-limited (N-) or P-limited (P-) conditions over 9 days in batch cultures (Mean \pm S.D., $n=5$ ). (A) Semi-log plot of growth curves (cell density $\mathrm{mL}^{-1}$ ) and specific growth rate $\left(\mathrm{d}^{-1}\right)$, (B) Dissolved $\mathrm{NO}_{3}^{-}$ concentration $(\mathrm{mM})$ and $\mathrm{PO}_{4}{ }^{3-}$ concentration $(\mu \mathrm{M})$ in N-limited cultures, $(\mathrm{C})$ Dissolved $\mathrm{NO}_{3}{ }^{-}$concentration $(\mathrm{mM})$ and $\mathrm{PO}_{4}{ }^{3-}$ concentration $(\mu \mathrm{M})$ in P-limited cultures, (D) Dissolved $\mathrm{NO}_{3}{ }^{-}$concentration $(\mathrm{mM})$ and $\mathrm{PO}_{4}{ }^{3-}$ concentration $(\mu \mathrm{M})$ in NP cultures.

Fig. 2. Cell volume $\left(\mu \mathrm{m}^{3}\right)$ of $T$. lutea grown under control (NP), N-limited (N-) or Plimited (P-) conditions in batch cultures. The thickness of the spindle-shaped figures is correlated with the volume distribution of 60 to 80 cells. Horizontal black lines indicate average volumes.

Fig. 3. Particulate carbon, nitrogen and phosphorus in T. lutea grown under control (NP), N-limited (N-) or P-limited (P-) conditions over 9 days in batch cultures (Mean \pm S.D. $\mathrm{n}=3$ ). (A) Carbon content per cell $\left(\mathrm{pg}\right.$ cell $\left.^{-1}\right)$, (B) Nitrogen content per unit cell carbon (mol/mol), (C) Phosphorus content per unit cell carbon ( $\mathrm{mol} / \mathrm{mol})$.

Fig. 4. Cellular pigment contents of T. lutea grown under control (NP), N-limited (N-) or P-limited (P-) conditions (Mean \pm S.D., $\mathrm{n}=3$ ), different letters indicate significant ( $\mathrm{p}$ $<0.05)$ differences at each day of culture. (A) Chl $a$ content per unit cell carbon $(\mathrm{mg} / \mathrm{g})$, (B) Chl $c$ content per unit cell carbon $(\mathrm{mg} / \mathrm{g})$, (C) Fucoxanthin content per unit cell carbon $(\mathrm{mg} / \mathrm{g})$.

Fig. 5. Chlorophyll $a$ fluorescence parameters of T. lutea grown under control (NP), Nlimited (N-) or P-limited (P-) conditions. Different letters indicate significant $(\mathrm{p}<0.05)$ differences at each day of culture (Mean \pm S.D., $n=3$ ). (A) Maximum photochemical efficiency of PSII ( $\left.\mathrm{F}_{\mathrm{v}} / \mathrm{F}_{\mathrm{m}}\right)$, (B) Effective photochemical efficiency of PSII ( $\left.\Phi_{\mathrm{II}}\right)$ under 
$300 \mu \mathrm{mol}$ photons $\mathrm{m}^{-2} \mathrm{~s}^{-1}$, (C) Photochemical quenching (qP) under $300 \mu \mathrm{mol}$ photons $\mathrm{m}^{-2} \mathrm{~s}^{-1}$, (D) Non-photochemical quenching (NPQ) under $300 \mu \mathrm{mol}$ photons $\mathrm{m}^{-2} \mathrm{~s}^{-1}$, (E) Proportions of $\mathrm{qN}_{\mathrm{f}}, \mathrm{qN}_{\mathrm{i}}$ and $\mathrm{qN}_{\mathrm{s}}$ in $\mathrm{qN}$ after a high irradiance $\left(1000 \mu \mathrm{mol}\right.$ photons $\mathrm{m}^{-2}$ $\left.\mathrm{s}^{-1}\right)$ in day-4 cells.

Fig. 6. Proximate biochemical composition of T. lutea grown under control (NP), Nlimited (N-) or P-limited (P-) conditions over 9 days in batch cultures (Mean \pm S.D., $\mathrm{n}=$ 3). (A) Soluble protein content per unit cell carbon (g/g), (B) Soluble carbohydrate content per unit cell carbon (g/g), (C) Fluorescence of microalgal cells stained with Nile red per unit cell carbon $\left(\mu \mathrm{g} \mathrm{C}^{-1}\right)$ as measurement of neutral lipid content, (D) Total lipid content per unit cell carbon $(\mathrm{g} / \mathrm{g})$.

Fig. 7. Transcriptional fold changes of 23 genes/isogenes coding for 10 enzymes involved in TAG and membrane lipid biosynthetic pathways in T. lutea, from triplicate cultures under (A) N-limited (N-) or (B) P-limited (P-) conditions. Colored squares indicate the regulation patterns on day 2 , day 4, and day 7 (red, upregulated; green, downregulated). For both treatments, day-2 NP cultures were used as calibrator. Asterisks indicate significant regulation differences compared with day-2 NP cultures ( $p$ $<0.01$ and $\left[\log _{2}\right.$ fold $>1$ or $\log _{2}$ fold $\left.<-1\right]$ or $p<0.05$ and $\left[\log _{2}\right.$ fold $>2$ or $\log _{2}$ fold $\left.<-2\right]$ ). See Table. S1 for correspondence between gene abbreviations and protein ID. Compounds: CDP-DAG, cytidine diphosphate diacylglycerol; DAG, diacylglycerol; DGDG, digalactosyldiacylglycerol; G3P, glycerol-3-phosphate; LPA, lysophosphatidic acid; MGDG, monogalactosyldiacylglycerol; PA, phosphatidic acid; PC, phosphatidylcholine; PE, phosphatidylethanolamine; PG, phosphatidylglycerol; PI, phosphatidylinositol; SQDG, sulfoquinovosyldiacylglycerol; TAG, triacylglycerol. 
Fig. 8. Lipid composition (expressed in mass \%) of T. lutea grown under control (NP), $\mathrm{N}$-limited (N-) or P-limited (P-) conditions. Different letters indicate significant ( $\mathrm{p}<$ 0.05) differences at each day of culture (Mean \pm S.D., $n=3$ ). (A) Lipid composition in plastidial membranes (SQDG, sulfoquinovosyldiacylglycerol; DGDG, digalactosyldiacylglycerol; $\quad$ MGDG, monogalactosyldiacylglycerol; $\quad$ PG, phosphatidylglycerol); (B) Lipid composition in non-plastidial membranes (PI, phosphatidylinositol; DGCC, diacylglycerol-3-carboxymethylcholine; DGTA, diacylglycerylhydroxymethyltrimethyl- $\beta$-alanine; DGTS, diacylglyceroltrimethylhomoserine; BLx1 and BLx2, two putative betaine lipids).

Fig. 9. Fatty acid composition (expressed in mol \%) in three main fractions of lipids extracted from T. lutea grown under control (NP), N-limited (N-), or P-limited (P-) conditions on day 4. Different letters indicate significant $(\mathrm{p}<0.05)$ differences $($ Mean \pm S.D., $n=3$ ). (A). Fatty acid composition in neutral lipids, (B). Fatty acid composition in glycolipids, (C). Fatty acid composition in phospho- and betaine lipids. Fatty acids: C14:0, myristic acid; C14:1n-5, myristoleic acid; C16:0, palmitic acid; C16:1n-7, palmitoleic acid; C16:2n-6, hexadecadienoic acid; C18:0, stearic acid; C18:1n-9, oleic acid; C18:2n-6, linoleic acid; C18:3n-3, $\alpha$-linolenic acid; C18:4n-3, stearidonic acid; C20:2n-6, eicosadienoic acid; C20:4n-6, arachidonic acid; C20:5n-3, eicosapentaenoic acid; C22:4n-6, docosatetraenoic acid; C22:5n-3, docosapentaenoic acid; C22:6n-3, docosahexaenoic acid.

\section{Supplementary data}

Supplementary Table. S1. List of enzymes and related genes analyzed by real-time qPCR and their respective primers. 


\section{References}

[1] C.B. Field, M.J. Behrenfeld, J.T. Randerson, P. Falkowski, Primary production of the biosphere: integrating terrestrial and oceanic components, Science. 281 (1998) 237-240. doi:10.1126/science.281.5374.237.

[2] L. Guidi, S. Chaffron, L. Bittner, D. Eveillard, A. Larhlimi, S. Roux, Y. Darzi, S. Audic, L. Berline, J.R. Brum, L.P. Coelho, J.C.I. Espinoza, S. Malviya, S. Sunagawa, C. Dimier, S. Kandels-Lewis, M. Picheral, J. Poulain, S. Searson, Tara Oceans Coordinators, L. Stemmann, F. Not, P. Hingamp, S. Speich, M. Follows, L. Karp-Boss, E. Boss, H. Ogata, S. Pesant, J. Weissenbach, P. Wincker, S.G. Acinas, P. Bork, C. de Vargas, D. Iudicone, M.B. Sullivan, J. Raes, E. Karsenti, C. Bowler, G. Gorsky, Plankton networks driving carbon export in the oligotrophic ocean, Nature. 532 (2016) 465-470. doi:10.1038/nature16942.

[3] S. Hemaiswarya, R. Raja, R.R. Kumar, V. Ganesan, C. Anbazhagan, Microalgae: a sustainable feed source for aquaculture, World J. Microbiol. Biotechnol. 27 (2011) 1737-1746. doi:10.1007/s11274-010-0632-z.

[4] R.H. Wijffels, M.J. Barbosa, An outlook on microalgal biofuels, Science. 329 (2010) 796-799. doi:10.1126/science.1189003.

[5] P. Spolaore, C. Joannis-Cassan, E. Duran, A. Isambert, Commercial applications of microalgae, J. Biosci. Bioeng. 101 (2006) 87-96. doi:10.1263/jbb.101.87.

[6] V. Mimouni, L. Ulmann, V. Pasquet, M. Mathieu, L. Picot, G. Bougaran, J.-P. Cadoret, A. Morant-Manceau, B. Schoefs, The potential of microalgae for the production of bioactive molecules of pharmaceutical interest, Curr. Pharm. Biotechnol. 13 (2012) 2733-2750. 
[7] M. Koller, A. Muhr, G. Braunegg, Microalgae as versatile cellular factories for valued products, Algal Res. 6 (2014) 52-63. doi:10.1016/j.algal.2014.09.002.

[8] S. Mobin, F. Alam, Some promising microalgal species for commercial applications: A review, Energy Procedia. $110 \quad$ (2017) 510-517. doi:10.1016/j.egypro.2017.03.177.

[9] W. Huang, F. Daboussi, Genetic and metabolic engineering in diatoms, Phil. Trans. R. Soc. B. 372 (2017) 20160411. doi:10.1098/rstb.2016.0411.

[10] O. Sayanova, V. Mimouni, L. Ulmann, A. Morant-Manceau, V. Pasquet, B. Schoefs, J.A. Napier, Modulation of lipid biosynthesis by stress in diatoms, Phil. Trans. R. Soc. B. 372 (2017) 20160407. doi:10.1098/rstb.2016.0407.

[11] L.D. Zhu, Z.H. Li, E. Hiltunen, Strategies for Lipid Production Improvement in Microalgae as a Biodiesel Feedstock, BioMed Res. Int. 2016 (2016) 8792548. doi:10.1155/2016/8792548.

[12] P.J. Harrison, P.A. Thompson, G.S. Calderwood, Effects of nutrient and light limitation on the biochemical composition of phytoplankton, J. Appl. Phycol. 2 (1990) 45-56. doi:10.1007/BF02179768.

[13] A. Sukenik, R. Wahnon, Biochemical quality of marine unicellular algae with special emphasis on lipid composition. I. Isochrysis galbana, Aquaculture. 97 (1991) 61-72. doi:10.1016/0044-8486(91)90279-G.

[14] P.A. Thompson, M. Guo, P.J. Harrison, Effects of variation in temperature. I. On the biochemical composition of eight species of marine phytoplankton, J. Phycol. 28 (1992) 481-488. doi:10.1111/j.0022-3646.1992.00481.x.

[15] I.A. Guschina, J.L. Harwood, Algal lipids and effect of the environment on their biochemistry, in: M.T. Arts, M.T. Brett, M. Kainz (Eds.), Lipids in Aquatic 
Ecosystems, Springer, New York, 2009: pp. 1-24. doi:10.1007/978-0-387-89366$2 \_1$.

[16] C.M. Moore, M.M. Mills, K.R. Arrigo, I. Berman-Frank, L. Bopp, P.W. Boyd, E.D. Galbraith, R.J. Geider, C. Guieu, S.L. Jaccard, T.D. Jickells, J.L. Roche, T.M. Lenton, N.M. Mahowald, E. Marañón, I. Marinov, J.K. Moore, T. Nakatsuka, A. Oschlies, M.A. Saito, T.F. Thingstad, A. Tsuda, O. Ulloa, Processes and patterns of oceanic nutrient limitation, Nat. Geosci. 6 (2013) 701710. doi:10.1038/ngeo1765.

[17] T. Brembu, A. Mühlroth, L. Alipanah, A.M. Bones, The effects of phosphorus limitation on carbon metabolism in diatoms, Phil. Trans. R. Soc. B. 372 (2017) 20160406. doi:10.1098/rstb.2016.0406.

[18] S. Lin, R.W. Litaker, W.G. Sunda, Phosphorus physiological ecology and molecular mechanisms in marine phytoplankton, J. Phycol. 52 (2016) 10-36. doi:10.1111/jpy.12365.

[19] P.G. Falkowski, J.A. Raven, Aquatic photosynthesis, Second, Princeton University Press, 2007.

[20] R. Geider, J. La Roche, Redfield revisited: variability of C:N:P in marine microalgae and its biochemical basis, Eur. J. Phycol. 37 (2002) 1-17. doi:10.1017/S0967026201003456.

[21] J.A. Raven, Interactions between Nitrogen and Phosphorus metabolism, in: W.C. Plaxton, H. Lambers (Eds.), Annual Plant Reviews Vol. 48, John Wiley \& Sons, Inc., 2015: pp. 187-214. doi:10.1002/9781118958841.ch7. 
[22] Y. Liu, X. Song, X. Cao, Z. Yu, Responses of photosynthetic characters of Skeletonema costatum to different nutrient conditions, J. Plankton Res. 35 (2013) 165-176. doi:10.1093/plankt/fbs080.

[23] N.W. Rasdi, J.G. Qin, Effect of N:P ratio on growth and chemical composition of Nannochloropsis oculata and Tisochrysis lutea, J. Appl. Phycol. 27 (2015) 22212230. doi:10.1007/s10811-014-0495-Z.

[24] J. Lai, Z. Yu, X. Song, X. Cao, X. Han, Responses of the growth and biochemical composition of Prorocentrum donghaiense to different nitrogen and phosphorus concentrations, J. Exp. Mar. Biol. Ecol. 405 (2011) 6-17. doi:10.1016/j.jembe.2011.05.010.

[25] H. Abida, L.-J. Dolch, C. Meï, V. Villanova, M. Conte, M.A. Block, G. Finazzi, O. Bastien, L. Tirichine, C. Bowler, F. Rébeillé, D. Petroutsos, J. Jouhet, E. Maréchal, Membrane glycerolipid remodeling triggered by nitrogen and phosphorus starvation in Phaeodactylum tricornutum, Plant Physiol. 167 (2015) 118-136. doi:10.1104/pp.114.252395.

[26] N. Lu, D. Wei, F. Chen, S.-T. Yang, Lipidomic profiling reveals lipid regulation in the snow alga Chlamydomonas nivalis in response to nitrate or phosphate deprivation, Process Biochem. $48 \quad$ (2013) 605-613. doi:10.1016/j.procbio.2013.02.028.

[27] K.I. Reitan, J.R. Rainuzzo, Y. Olsen, Effect of nutrient limitation on fatty acid and lipid content of marine microalgae, J. Phycol. 30 (1994) 972-979. doi:10.1111/j.0022-3646.1994.00972.x.

[28] Q. Hu, M. Sommerfeld, E. Jarvis, M. Ghirardi, M. Posewitz, M. Seibert, A. Darzins, Microalgal triacylglycerols as feedstocks for biofuel production: 
perspectives and advances, Plant J. 54 (2008) 621-639. doi:10.1111/j.1365313X.2008.03492.x.

[29] K.K. Sharma, H. Schuhmann, P.M. Schenk, High lipid induction in microalgae for biodiesel production, Energies. 5 (2012) 1532-1553. doi:10.3390/en5051532.

[30] I. Khozin-Goldberg, Z. Cohen, The effect of phosphate starvation on the lipid and fatty acid composition of the fresh water eustigmatophyte Monodus subterraneus, Phytochemistry. 67 (2006) 696-701. doi:10.1016/j.phytochem.2006.01.010.

[31] B.A.S. Van Mooy, H.F. Fredricks, B.E. Pedler, S.T. Dyhrman, D.M. Karl, M. Koblížek, M.W. Lomas, T.J. Mincer, L.R. Moore, T. Moutin, M.S. Rappé, E.A. Webb, Phytoplankton in the ocean use non-phosphorus lipids in response to phosphorus scarcity, Nature. 458 (2009) 69-72. doi:10.1038/nature07659.

[32] A. Shemi, D. Schatz, H.F. Fredricks, B.A.S. Van Mooy, Z. Porat, A. Vardi, Phosphorus starvation induces membrane remodeling and recycling in Emiliania huxleyi, New Phytol. 211 (2016) 886-898. doi:10.1111/nph.13940.

[33] A. Mühlroth, P. Winge, A.E. Assimi, J. Jouhet, E. Marechal, M.F. HohmannMarriott, O. Vadstein, A.M. Bones, Mechanisms of phosphorus acquisition and lipid class remodelling under P limitation in a marine microalga, Plant Physiol. 175 (2017) 1543-1559. doi:10.1104/pp.17.00621.

[34] J.P. Cañavate, I. Armada, I. Hachero-Cruzado, Interspecific variability in phosphorus-induced lipid remodelling among marine eukaryotic phytoplankton, New Phytol. 213 (2017) 700-713. doi:10.1111/nph.14179.

[35] J.P. Cañavate, I. Armada, I. Hachero-Cruzado, Aspects of phosphorus physiology associated with phosphate-induced polar lipid remodelling in marine microalgae, J. Plant Physiol. 214 (2017) 28-38. doi:10.1016/j.jplph.2017.03.019. 
[36] E.M. Bendif, I. Probert, D.C. Schroeder, C. de Vargas, On the description of Tisochrysis lutea gen. nov. sp. nov. and Isochrysis nuda sp. nov. in the Isochrysidales, and the transfer of Dicrateria to the Prymnesiales (Haptophyta), J. Appl. Phycol. 25 (2013) 1763-1776. doi:10.1007/s10811-013-0037-0.

[37] M.R. Brown, S.W. Jeffrey, J.K. Volkman, G.A. Dunstan, Nutritional properties of microalgae for mariculture, Aquaculture. 151 (1997) 315-331. doi:10.1016/S0044-8486(96)01501-3.

[38] P. Coutteau, P. Sorgeloos, The use of algal substitutes and the requirement for live algae in the hatchery and nursery rearing of bivalve molluscs: An international survey, J. Shellfish Res. 11 (1992) 467-476.

[39] C.-P. Liu, L.-P. Lin, Ultrastructural study and lipid formation of Isochrysis sp. CCMP1324, Bot. Bull. Acad. Sin. 42 (2001) 207-214.

[40] A.P. Simopoulos, Essential fatty acids in health and chronic disease, Am. J. Clin. Nutr. 70 (1999) 560s-569s. doi:10.1093/ajcn/70.3.560s.

[41] J.N.C. Whyte, N. Bourne, N.G. Ginther, C.A. Hodgson, Compositional changes in the larva to juvenile development of the scallop Crassadoma gigantea (Gray), J. Exp. Mar. Biol. Ecol. 163 (1992) 13-29. doi:10.1016/0022-0981(92)90144-Y.

[42] Y. Marty, F. Delaunay, J. Moal, J.-F. Samain, Changes in the fatty acid composition of Pecten maximus (L.) during larval development, J. Exp. Mar. Biol. Ecol. 163 (1992) 221-234. doi:10.1016/0022-0981(92)90051-B.

[43] F. Delaunay, Y. Marty, J. Moal, J.-F. Samain, The effect of monospecific algal diets on growth and fatty acid composition of Pecten maximus (L.) larvae, J. Exp. Mar. Biol. Ecol. 173 (1993) 163-179. doi:10.1016/0022-0981(93)90051-O. 
[44] S.M. Myklestad, E. Granum, Chapter 4.2 - Biology of (1,3)- $\beta$-glucans and related glucans in Protozoans and Chromistans, in: A. Bacic, G.B. Fincher, B.A. Stone (Eds.), Chemistry, Biochemistry, and Biology of 1-3 Beta Glucans Related Polysaccharides, Academic Press, San Diego, 2009: pp. 353-385. doi:10.1016/B978-0-12-373971-1.00010-8.

[45] Q. Shi, H. Araie, R.K. Bakku, Y. Fukao, R. Rakwal, I. Suzuki, Y. Shiraiwa, Proteomic analysis of lipid body from the alkenone-producing marine haptophyte alga Tisochrysis lutea, Proteomics. $15 \quad$ (2015) 4145-4158. doi:10.1002/pmic.201500010.

[46] I.T. Marlowe, J.C. Green, A.C. Neal, S.C. Brassell, G. Eglinton, P.A. Course, Long chain (n-C37-C39) alkenones in the Prymnesiophyceae. Distribution of alkenones and other lipids and their taxonomic significance, Br. Phycol. J. 19 (1984) 203-216. doi:10.1080/00071618400650221.

[47] G. Carrier, C. Baroukh, C. Rouxel, L. Duboscq-Bidot, N. Schreiber, G. Bougaran, Draft genomes and phenotypic characterization of Tisochrysis lutea strains. Toward the production of domesticated strains with high added value, Algal Res. 29 (2018) 1-11. doi:10.1016/j.algal.2017.10.017.

[48] G. Carrier, M. Garnier, L.L. Cunff, G. Bougaran, I. Probert, C.D. Vargas, E. Corre, J.-P. Cadoret, B. Saint-Jean, Comparative transcriptome of wild type and selected strains of the microalgae Tisochrysis lutea provides insights into the genetic basis, lipid metabolism and the life cycle, PLoS One. 9 (2014) e86889. doi:10.1371/journal.pone.0086889.

[49] S. Thiriet-Rupert, G. Carrier, C. Trottier, D. Eveillard, B. Schoefs, G. Bougaran, J.-P. Cadoret, B. Chénais, B. Saint-Jean, Identification of transcription factors 
involved in the phenotype of a domesticated oleaginous microalgae strain of Tisochrysis lutea, Algal Res. 30 (2018) 59-72. doi:10.1016/j.algal.2017.12.011.

[50] M. Garnier, G. Carrier, H. Rogniaux, E. Nicolau, G. Bougaran, B. Saint-Jean, J.P. Cadoret, Comparative proteomics reveals proteins impacted by nitrogen deprivation in wild-type and high lipid-accumulating mutant strains of Tisochrysis lutea, J. Proteomics. $105 \quad$ (2014) 107-120. doi:10.1016/j.jprot.2014.02.022.

[51] M. Garnier, G. Bougaran, M. Pavlovic, J.-B. Berard, G. Carrier, A. Charrier, F. Le Grand, E. Lukomska, C. Rouxel, N. Schreiber, J.-P. Cadoret, H. Rogniaux, B. Saint-Jean, Use of a lipid rich strain reveals mechanisms of nitrogen limitation and carbon partitioning in the haptophyte Tisochrysis lutea, Algal Res. 20 (2016) 229-248. doi:10.1016/j.algal.2016.10.017.

[52] F. Da Costa, F. Le Grand, C. Quéré, G. Bougaran, J.P. Cadoret, R. Robert, P. Soudant, Effects of growth phase and nitrogen limitation on biochemical composition of two strains of Tisochrysis lutea, Algal Res. 27 (2017) 177-189. doi:10.1016/j.algal.2017.09.003.

[53] G. Bougaran, O. Bernard, A. Sciandra, Modeling continuous cultures of microalgae colimited by nitrogen and phosphorus, J. Theor. Biol. 265 (2010) 443-454. doi:10.1016/j.jtbi.2010.04.018.

[54] F. Mairet, O. Bernard, P. Masci, T. Lacour, A. Sciandra, Modelling neutral lipid production by the microalga Isochrysis aff. galbana under nitrogen limitation, Bioresour. Technol. 102 (2011) 142-149. doi:10.1016/j.biortech.2010.06.138.

[55] T. Lacour, A. Sciandra, A. Talec, P. Mayzaud, O. Bernard, Neutral lipid and carbohydrate productivities as a response to nitrogen status in Isochrysis Sp. (t- 
Iso; Haptophyceae): starvation versus limitation, J. Phycol. 48 (2012) 647-656. doi:10.1111/j.1529-8817.2012.01154.x.

[56] P.R. Walne, Experiments in the large-scale culture of the larvae of Ostrea edulis L, Fish. Investig. 25 (1966) 1-55.

[57] G. Bougaran, La co-limitation par l'azote et le phosphore : étude des mécanismes chez la microalgue Tisochrysis lutea, Thèse de doctorat, Université de Nantes, 2014.

[58] American Public Health Association, APHA method 4500-NO3: standard methods for the examination of water and wastewater, 1992. http://archive.org/details/gov.law.apha.method.4500-no3.1992.

[59] J. Murphy, J.P. Riley, A single-solution method for the determination of soluble phosphate in sea water, J. Mar. Biol. Assoc. U. K. 37 (1958) 9-14. doi:10.1017/S0025315400014776.

[60] M. Pujo-Pay, P. Raimbault, Improvement of the wet-oxidation procedure for simultaneous determination of particulate organic nitrogen and phosphorus collected on filters, Mar. Ecol. Prog. Ser. 105 (1994) 203-207. http://www.jstor.org/stable/24842902.

[61] K. Roháček, M. Bertrand, B. Moreau, B. Jacquette, C. Caplat, A. MorantManceau, B. Schoefs, Relaxation of the non-photochemical chlorophyll fluorescence quenching in diatoms: kinetics, components and mechanisms, Phil. Trans. R. Soc. B. 369 (2014) 20130241. doi:10.1098/rstb.2013.0241.

[62] K. Roháček, J. Soukupová, M. Barták, Chlorophyll fluorescence: a wonderful tool to study plant physiology and plant stress, in: B. Schoefs (Eds.), Plant Cell 
Compartments-Selected Topics, Research Signpost, Kerala India, 2008: pp. 41104.

[63] M.M. Bradford, A rapid and sensitive method for the quantitation of microgram quantities of protein utilizing the principle of protein-dye binding, Anal. Biochem. 72 (1976) 248-254.

[64] M. Dubois, K. Gilles, J.K. Hamilton, P.A. Rebers, F. Smith, A colorimetric method for the determination of sugars, Nature. 168 (1951) 167.

[65] P. Heydarizadeh, W. Boureba, M. Zahedi, B. Huang, B. Moreau, E. Lukomska, A. Couzinet-Mossion, G. Wielgosz-Collin, V. Martin-Jézéquel, G. Bougaran, J. Marchand, B. Schoefs, Response of CO2-starved diatom Phaeodactylum tricornutum to light intensity transition, Phil. Trans. R. Soc. B. 372 (2017) 20160396. doi:10.1098/rstb.2016.0396.

[66] E.G. Bligh, W.J. Dyer, A rapid method of total lipid extraction and purification, Can. J. Biochem. Physiol. 37 (1959) 911-917. doi:10.1139/o59-099.

[67] J.B. Marsh, D.B. Weinstein, Simple charring method for determination of lipids, J. Lipid Res. 7 (1966) 574-576. http://www.jlr.org/content/7/4/574.

[68] T. White, S. Bursten, D. Federighi, R.A. Lewis, E. Nudelman, High-resolution separation and quantification of neutral lipid and phospholipid species in mammalian cells and sera by multi-one-dimensional thin-layer chromatography, Anal. Biochem. 258 (1998) 109-117. doi:10.1006/abio.1997.2545.

[69] J.C. Dittmer, R.L. Lester, A simple, specific spray for the detection of phospholipids on thin-layer chromatograms, J. Lipid Res. 5 (1964) 126-127.

[70] H.T. Slover, E. Lanza, Quantitative analysis of food fatty acids by capillary gas chromatography, J. Am. Oil Chem. Soc. 56 (1979) 933. doi:10.1007/BF02674138. 
[71] S. Zhao, R.D. Fernald, Comprehensive algorithm for quantitative real-time polymerase chain reaction, J. Comput. Biol. 12 (2005) 1047-1064. doi:10.1089/cmb.2005.12.1047.

[72] C. Bowler, A.E. Allen, J.H. Badger, J. Grimwood, K. Jabbari, A. Kuo, U. Maheswari, C. Martens, F. Maumus, R.P. Otillar, E. Rayko, A. Salamov, K. Vandepoele, B. Beszteri, A. Gruber, M. Heijde, M. Katinka, T. Mock, K. Valentin, F. Verret, J.A. Berges, C. Brownlee, J.-P. Cadoret, A. Chiovitti, C.J. Choi, S. Coesel, A.D. Martino, J.C. Detter, C. Durkin, A. Falciatore, J. Fournet, M. Haruta, M.J.J. Huysman, B.D. Jenkins, K. Jiroutova, R.E. Jorgensen, Y. Joubert, A. Kaplan, N. Kröger, P.G. Kroth, J.L. Roche, E. Lindquist, M. Lommer, V. Martin-Jézéquel, P.J. Lopez, S. Lucas, M. Mangogna, K. McGinnis, L.K. Medlin, A. Montsant, M.-P.O. Secq, C. Napoli, M. Obornik, M.S. Parker, J.-L. Petit, B.M. Porcel, N. Poulsen, M. Robison, L. Rychlewski, T.A. Rynearson, J. Schmutz, H. Shapiro, M. Siaut, M. Stanley, M.R. Sussman, A.R. Taylor, A. Vardi, P. von Dassow, W. Vyverman, A. Willis, L.S. Wyrwicz, D.S. Rokhsar, J. Weissenbach, E.V. Armbrust, B.R. Green, Y. Van de Peer, I.V. Grigoriev, The Phaeodactylum genome reveals the evolutionary history of diatom genomes, Nature. 456 (2008) 239-244. doi:10.1038/nature07410.

[73] B.A. Read, J. Kegel, M.J. Klute, A. Kuo, S.C. Lefebvre, F. Maumus, C. Mayer, J. Miller, A. Monier, A. Salamov, J. Young, M. Aguilar, J.-M. Claverie, S. Frickenhaus, K. Gonzalez, E.K. Herman, Y.-C. Lin, J. Napier, H. Ogata, A.F. Sarno, J. Shmutz, D. Schroeder, C. de Vargas, F. Verret, P. von Dassow, K. Valentin, Y.V. de Peer, G. Wheeler, E. huxleyi A. Consortium, A.E. Allen, K. Bidle, M. Borodovsky, C. Bowler, C. Brownlee, J.M. Cock, M. Elias, V.N. 
Gladyshev, M. Groth, C. Guda, A. Hadaegh, M.D. Iglesias-Rodriguez, J. Jenkins, B.M. Jones, T. Lawson, F. Leese, E. Lindquist, A. Lobanov, A. Lomsadze, S.-B. Malik, M.E. Marsh, L. Mackinder, T. Mock, B. Mueller-Roeber, A. Pagarete, M. Parker, I. Probert, H. Quesneville, C. Raines, S.A. Rensing, D.M. Riaño-Pachón, S. Richier, S. Rokitta, Y. Shiraiwa, D.M. Soanes, M. van der Giezen, T.M. Wahlund, B. Williams, W. Wilson, G. Wolfe, L.L. Wurch, J.B. Dacks, C.F. Delwiche, S.T. Dyhrman, G. Glöckner, U. John, T. Richards, A.Z. Worden, X. Zhang, I.V. Grigoriev, Pan genome of the phytoplankton Emiliania underpins its global distribution, Nature. 499 (2013) 209-213. doi:10.1038/nature12221.

[74] S.F. Altschul, W. Gish, W. Miller, E.W. Myers, D.J. Lipman, Basic local alignment search tool, J. Mol. Biol. 215 (1990) 403-410. doi:10.1016/S00222836(05)80360-2.

[75] M.W. Pfaffl, A. Tichopad, C. Prgomet, T.P. Neuvians, Determination of stable housekeeping genes, differentially regulated target genes and sample integrity: BestKeeper - Excel-based tool using pair-wise correlations, Biotechnol. Lett. 26 (2004) 509-515. doi:10.1023/B:BILE.0000019559.84305.47.

[76] K.J. Livak, T.D. Schmittgen, Analysis of relative gene expression data using realtime quantitative PCR and the 2- $\Delta \Delta \mathrm{CT}$ method, Methods. 25 (2001) 402-408. doi:10.1006/meth.2001.1262.

[77] M.G. Chapman, A.J. Underwood, Ecological patterns in multivariate assemblages: information and interpretation of negative values in ANOSIM tests, Mar. Ecol. Prog. Ser. 180 (1999) 257-265. doi:10.3354/meps180257.

[78] J. Oksanen, F.G. Blanchet, M. Friendly, R. Kindt, P. Legendre, D. McGlinn, P.R. Minchin, R.B. O’Hara, G.L. Simpson, P. Solymos, M.H.H. Stevens, E. Szoecs, H. 
Wagner, vegan: Community Ecology Package, 2018. https://CRAN.Rproject.org/package=vegan .

[79] G.-Y. Rhee, Phosphate uptake under nitrate limitation by Scenedesmus sp. and its ecological implications, J. Phycol. 10 (1974) 470-475. doi:10.1111/j.15298817.1974.tb02742.x.

[80] M.B. Ginzberg, R. Kafri, M. Kirschner, On being the right (cell) size, Science. 348 (2015) 1245075. doi:10.1126/science.1245075.

[81] M. Li, X. Shi, C. Guo, S. Lin, Phosphorus deficiency inhibits cell division but not growth in the dinoflagellate Amphidinium carterae, Front. Microbiol. 7 (2016) 826. doi:10.3389/fmicb.2016.00826.

[82] C. Zhang, S. Lin, L. Huang, W. Lu, M. Li, S. Liu, Suppression subtraction hybridization analysis revealed regulation of some cell cycle and toxin genes in Alexandrium catenella by phosphate limitation, Harmful Algae. 39 (2014) 26-39. doi:10.1016/j.hal.2014.06.005.

[83] M. Li, L. Li, X. Shi, L. Lin, S. Lin, Effects of phosphorus deficiency and adenosine 5'-triphosphate (ATP) on growth and cell cycle of the dinoflagellate Prorocentrum donghaiense, Harmful Algae. $47 \quad$ (2015) 35-41. doi:10.1016/j.hal.2015.05.013.

[84] J.P. Thornber, Chlorophyll-proteins: Light-harvesting and reaction center components of plants, Annu. Rev. Plant Physiol. 26 (1975) 127-158. doi:10.1146/annurev.pp.26.060175.001015.

[85] A. Roopnarain, V.M. Gray, S.D. Sym, Phosphorus limitation and starvation effects on cell growth and lipid accumulation in Isochrysis galbana U4 for 
biodiesel production, Bioresour. Technol. $156 \quad$ (2014) 408-411. doi:10.1016/j.biortech.2014.01.092.

[86] S.M. Kim, S.-W. Kang, O.-N. Kwon, D. Chung, C.-H. Pan, Fucoxanthin as a major carotenoid in Isochrysis aff. galbana: Characterization of extraction for commercial application, J. Korean Soc. Appl. Biol. Chem. 55 (2012) 477-483. doi:10.1007/s13765-012-2108-3.

[87] A.J. Young, G. Britton, Carotenoids and oxidative stress, in: M. Baltscheffsky (Eds.), Current Research in Photosynthesis, Springer, Dordrecht, 1990: pp. 33813384. doi:10.1007/978-94-009-0511-5_759.

[88] M. Di Valentin, C. Büchel, G.M. Giacometti, D. Carbonera, Chlorophyll triplet quenching by fucoxanthin in the fucoxanthin-chlorophyll protein from the diatom Cyclotella meneghiniana, Biochem. Biophys. Res. Commun. 427 (2012) 637641. doi:10.1016/j.bbrc.2012.09.113.

[89] D.D. Wykoff, J.P. Davies, A. Melis, A.R. Grossman, The regulation of photosynthetic electron transport during nutrient deprivation in Chlamydomonas reinhardtii, Plant Physiol. 117 (1998) 129-139. doi:10.1104/pp.117.1.129.

[90] R.A. Chylla, J. Whitmarsh, Inactive photosystem II complexes in leaves: turnover rate and quantitation, Plant Physiol. 90 (1989) 765-772.

[91] A. Brooks, Effects of phosphorus nutrition on ribulose-1,5-bisphosphate carboxylase activation, photosynthetic quantum yield and amounts of some calvin-cycle metabolites in spinach leaves, Funct. Plant Biol. 13 (1986) 221-237. doi:10.1071/pp9860221. 
[92] J. Jacob, D.W. Lawlor, In vivo photosynthetic electron transport does not limit photosynthetic capacity in phosphate-deficient sunflower and maize leaves, Plant Cell Environ. 16 (1993) 785-795. doi:10.1111/j.1365-3040.1993.tb00500.x.

[93] P. Müller, X.-P. Li, K.K. Niyogi, Non-photochemical quenching. A response to excess light energy, Plant Physiol. $125 \quad$ (2001) 1558-1566. doi:10.1104/pp.125.4.1558.

[94] L. Zhang, L. Li, J. Liu, Comparison of the photosynthetic characteristics of two Isochrysis galbana strains under high light, Bot. Mar. 57 (2014) 477-481. doi:10.1515/bot-2014-0056.

[95] K. Roháček, Method for resolution and quantification of components of the nonphotochemical quenching (qN), Photosynth. Res. 105 (2010) 101-113. doi:10.1007/s11120-010-9564-6.

[96] S. Menden-Deuer, E.J. Lessard, Carbon to volume relationships for dinoflagellates, diatoms, and other protist plankton, Limnol. Oceanogr. 45 (2000) 569-579. doi:10.4319/lo.2000.45.3.0569.

[97] J. Marchetti, G. Bougaran, L. Le Dean, C. Mégrier, E. Lukomska, R. Kaas, E. Olivo, R. Baron, R. Robert, J.P. Cadoret, Optimizing conditions for the continuous culture of Isochrysis affinis galbana relevant to commercial hatcheries, $\quad$ Aquaculture. $\quad 326-329 \quad$ (2012) 106-115. doi:10.1016/j.aquaculture.2011.11.020.

[98] M.R. Brown, C.D. Garland, S.W. Jeffrey, I.D. Jameson, J.M. Leroi, The gross and amino acid compositions of batch and semi-continuous cultures of Isochrysis sp. (clone T.ISO), Pavlova lutheri and Nannochloropsis oculata, J. Appl. Phycol. 5 (1993) 285-296. doi:10.1007/BF02186231. 
[99] F. Ge, W. Huang, Z. Chen, C. Zhang, Q. Xiong, C. Bowler, J. Yang, J. Xu, H. Hu, Methylcrotonyl-CoA carboxylase regulates triacylglycerol accumulation in the model diatom Phaeodactylum tricornutum, Plant Cell. 26 (2014) 1681-1697. doi:10.1105/tpc.114.124982.

[100] S.T. Dyhrman, Nutrients and their acquisition: Phosphorus physiology in microalgae, in: M.A. Borowitzka, J. Beardall, J.A. Raven (Eds.), The Physiology of Microalgae, Springer, Cham, 2016: pp. 155-183. doi:10.1007/978-3-31924945-2_8.

[101] H.-T. Wang, C.-H. Yao, J.-N. Ai, X.-P. Cao, S. Xue, W. Wang, Identification of carbohydrates as the major carbon sink of the marine microalga Isochrysis zhangjiangensis (Haptophyta) and optimization of its productivity by nitrogen manipulation, Bioresour. Technol. $171 \quad$ (2014) 298-304. doi:10.1016/j.biortech.2014.08.090.

[102] Z.-K. Yang, J.-W. Zheng, Y.-F. Niu, W.-D. Yang, J.-S. Liu, H.-Y. Li, Systemslevel analysis of the metabolic responses of the diatom Phaeodactylum tricornutum to phosphorus stress, Environ. Microbiol. 16 (2014) 1793-1807. doi:10.1111/1462-2920.12411.

[103] J. Valenzuela, A. Mazurie, R.P. Carlson, R. Gerlach, K.E. Cooksey, B.M. Peyton, M.W. Fields, Potential role of multiple carbon fixation pathways during lipid accumulation in Phaeodactylum tricornutum, Biotechnol. Biofuels. 5 (2012) 40. doi:10.1186/1754-6834-5-40.

[104] R. Huerlimann, E.J. Steinig, H. Loxton, K.R. Zenger, D.R. Jerry, K. Heimann, The effect of nitrogen limitation on acetyl-CoA carboxylase expression and fatty 
acid content in Chromera velia and Isochrysis aff. galbana (TISO), Gene. 543 (2014) 204-211. doi:10.1016/j.gene.2014.04.022.

[105] T.D. Nalder, M.R. Miller, M.A. Packer, Changes in lipid class content and composition of Isochrysis sp. (T-Iso) grown in batch culture, Aquac. Int. 23 (2015) 1293-1312. doi:10.1007/s10499-015-9884-9.

[106] D. Simionato, M.A. Block, N. La Rocca, J. Jouhet, E. Maréchal, G. Finazzi, T. Morosinotto, The response of Nannochloropsis gaditana to nitrogen starvation includes de novo biosynthesis of triacylglycerols, a decrease of chloroplast galactolipids, and reorganization of the photosynthetic apparatus, Eukaryot. Cell. 12 (2013) 665-676. doi:10.1128/EC.00363-12.

[107] G.J.O. Martin, D.R.A. Hill, I.L.D. Olmstead, A. Bergamin, M.J. Shears, D.A. Dias, S.E. Kentish, P.J. Scales, C.Y. Botté, D.L. Callahan, Lipid profile remodeling in response to nitrogen deprivation in the microalgae Chlorella sp. (Trebouxiophyceae) and Nannochloropsis sp. (Eustigmatophyceae), PLoS One. 9 (2014) e103389. doi:10.1371/journal.pone.0103389.

[108] S. Li, J. Xu, J. Chen, J. Chen, C. Zhou, X. Yan, The major lipid changes of some important diet microalgae during the entire growth phase, Aquaculture. 428-429 (2014) 104-110. doi:10.1016/j.aquaculture.2014.02.032.

[109] E.P. Kennedy, The biological synthesis of phospholipids, Can. J. Biochem. Physiol. 34 (1956) 334-348.

[110] Y. Li-Beisson, F. Beisson, W. Riekhof, Metabolism of acyl-lipids in Chlamydomonas reinhardtii, Plant J. 82 (2015) 504-522. doi:10.1111/tpj.12787.

[111] K. Yoon, D. Han, Y. Li, M. Sommerfeld, Q. Hu, Phospholipid:diacylglycerol acyltransferase is a multifunctional enzyme involved in membrane lipid turnover 
and degradation while synthesizing triacylglycerol in the unicellular green microalga Chlamydomonas reinhardtii, Plant Cell. 24 (2012) 3708-3724. doi:10.1105/tpc.112.100701.

[112] J. Marchetti, F. da Costa, G. Bougaran, C. Quéré, P. Soudant, R. Robert, The combined effects of blue light and dilution rate on lipid class and fatty acid composition of Tisochrysis lutea, J. Appl. Phycol. 30 (2018) 1483-1494. doi:10.1007/s10811-017-1340-y.

[113] Y. Li-Beisson, B. Shorrosh, F. Beisson, M.X. Andersson, V. Arondel, P.D. Bates, S. Baud, D. Bird, A. DeBono, T.P. Durrett, R.B. Franke, I.A. Graham, K. Katayama, A.A. Kelly, T. Larson, J.E. Markham, M. Miquel, I. Molina, I. Nishida, O. Rowland, L. Samuels, K.M. Schmid, H. Wada, R. Welti, C. Xu, R. Zallot, J. Ohlrogge, Acyl-lipid metabolism, Arab. Book Am. Soc. Plant Biol. 8 (2010) e0133. doi:10.1199/tab.0133.

[114] R. Goss, J. Nerlich, B. Lepetit, S. Schaller, A. Vieler, C. Wilhelm, The lipid dependence of diadinoxanthin de-epoxidation presents new evidence for a macrodomain organization of the diatom thylakoid membrane, J. Plant Physiol. 166 (2009) 1839-1854. doi:10.1016/j.jplph.2009.05.017.

[115] B. Lepetit, R. Goss, T. Jakob, C. Wilhelm, Molecular dynamics of the diatom thylakoid membrane under different light conditions, Photosynth. Res. 111 (2012) 245-257. doi:10.1007/s11120-011-9633-5.

[116] K. Kobayashi, K. Endo, H. Wada, Roles of Lipids in Photosynthesis, in: Y. Nakamura, Y. Li-Beisson (Eds.), Lipids in Plant and Algae Development, Springer, Cham, 2016: pp. 21-49. doi:10.1007/978-3-319-25979-6_2. 
[117] B. Yu, C. Benning, Anionic lipids are required for chloroplast structure and function in Arabidopsis, Plant J. Cell Mol. Biol. 36 (2003) 762-770.

[118] A. Minoda, K. Sonoike, K. Okada, N. Sato, M. Tsuzuki, Decrease in the efficiency of the electron donation to tyrosine Z of photosystem II in an SQDGdeficient mutant of Chlamydomonas, FEBS Lett. 553 (2003) 109-112.

[119] J. Popko, C. Herrfurth, K. Feussner, T. Ischebeck, T. Iven, R. Haslam, M. Hamilton, O. Sayanova, J. Napier, I. Khozin-Goldberg, I. Feussner, Metabolome analysis reveals betaine lipids as major source for triglyceride formation, and the accumulation of sedoheptulose during nitrogen-starvation of Phaeodactylum tricornutum, PLoS One. 11 (2016) e0164673. doi:10.1371/journal.pone.0164673.

[120] C. Xu, C. Andre, J. Fan, J. Shanklin, Cellular organization of triacylglycerol biosynthesis in microalgae, Subcell. Biochem. 86 (2016) 207-221. doi:10.1007/978-3-319-25979-6_9.

[121] W. Eichenberger, C. Gribi, Lipids of Pavlova lutheri: Cellular site and metabolic role of DGCC, Phytochemistry. 45 (1997) 1561-1567. doi:10.1016/S00319422(97)00201-X.

[122] J.A. Raven, The evolution of autotrophy in relation to phosphorus requirement, J. Exp. Bot. 64 (2013) 4023-4046. doi:10.1093/jxb/ert306.

[123] A. Mühlroth, K. Li, G. Røkke, P. Winge, Y. Olsen, M.F. Hohmann-Marriott, O. Vadstein, A.M. Bones, Pathways of lipid metabolism in marine algae, coexpression network, bottlenecks and candidate genes for enhanced production of EPA and DHA in species of Chromista, Mar. Drugs. 11 (2013) 4662-4697. doi:10.3390/md11114662. 
[124] F. Guihéneuf, L. Ulmann, G. Tremblin, V. Mimouni, Light-dependent utilization of two radiolabelled carbon sources, sodium bicarbonate and sodium acetate, and relationships with long chain polyunsaturated fatty acid synthesis in the microalga Pavlova lutheri (Haptophyta), Eur. J. Phycol. 46 (2011) 143-152. doi:10.1080/09670262.2011.577912.

[125] P. Heydarizadeh, I. Poirier, D. Loizeau, L. Ulmann, V. Mimouni, B. Schoefs, M. Bertrand, Plastids of Marine Phytoplankton Produce Bioactive Pigments and Lipids, Mar. Drugs. 11 (2013) 3425-3471. doi:10.3390/md11093425.

[126] G. Breuer, P.P. Lamers, D.E. Martens, R.B. Draaisma, R.H. Wijffels, The impact of nitrogen starvation on the dynamics of triacylglycerol accumulation in nine microalgae strains, Bioresour. Technol. 124 (2012) 217-226. doi:10.1016/j.biortech.2012.08.003. 
A

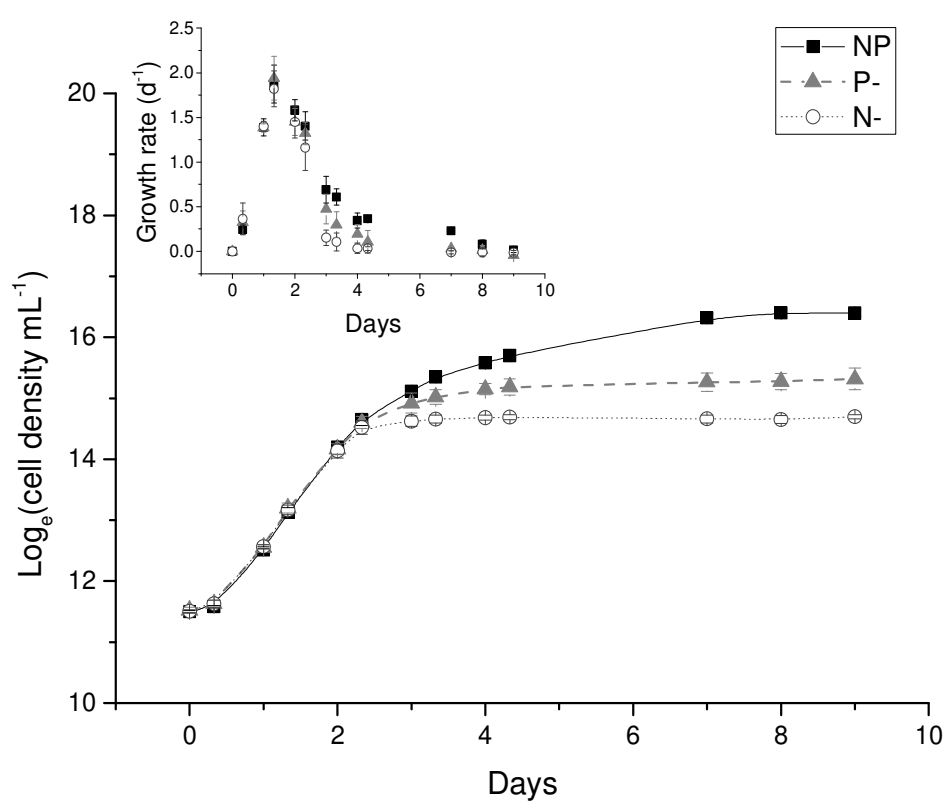

B

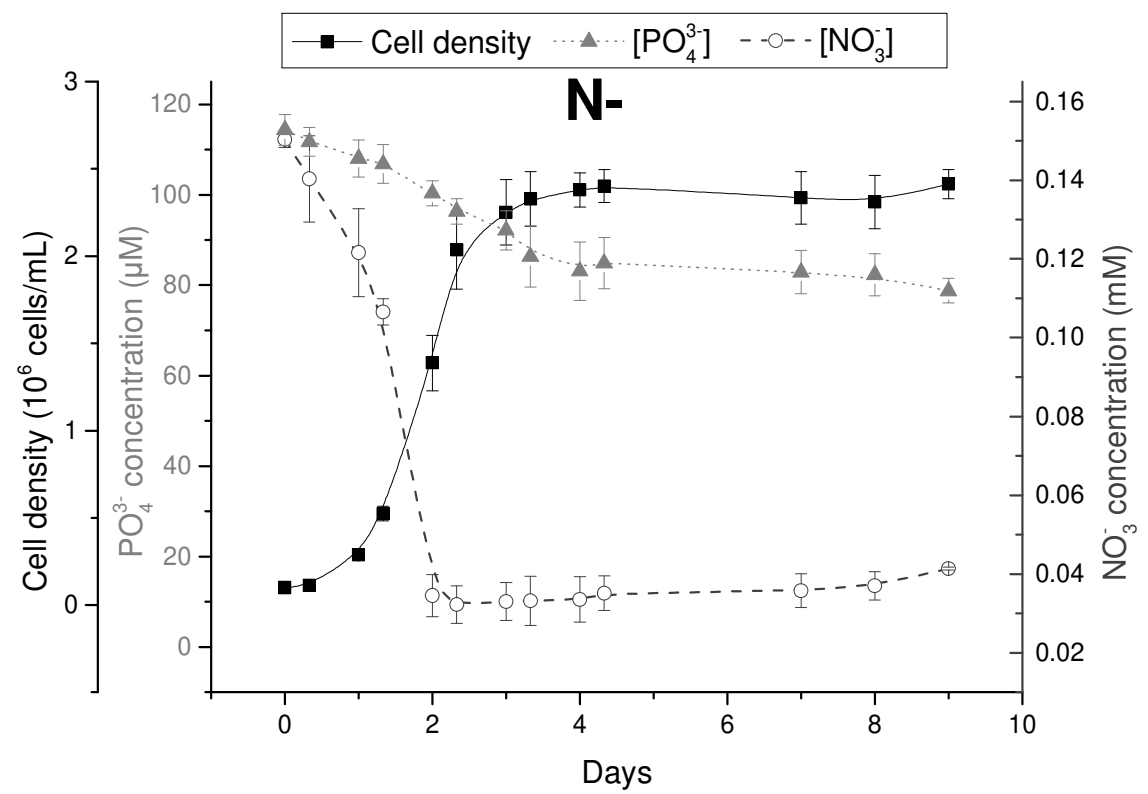


C

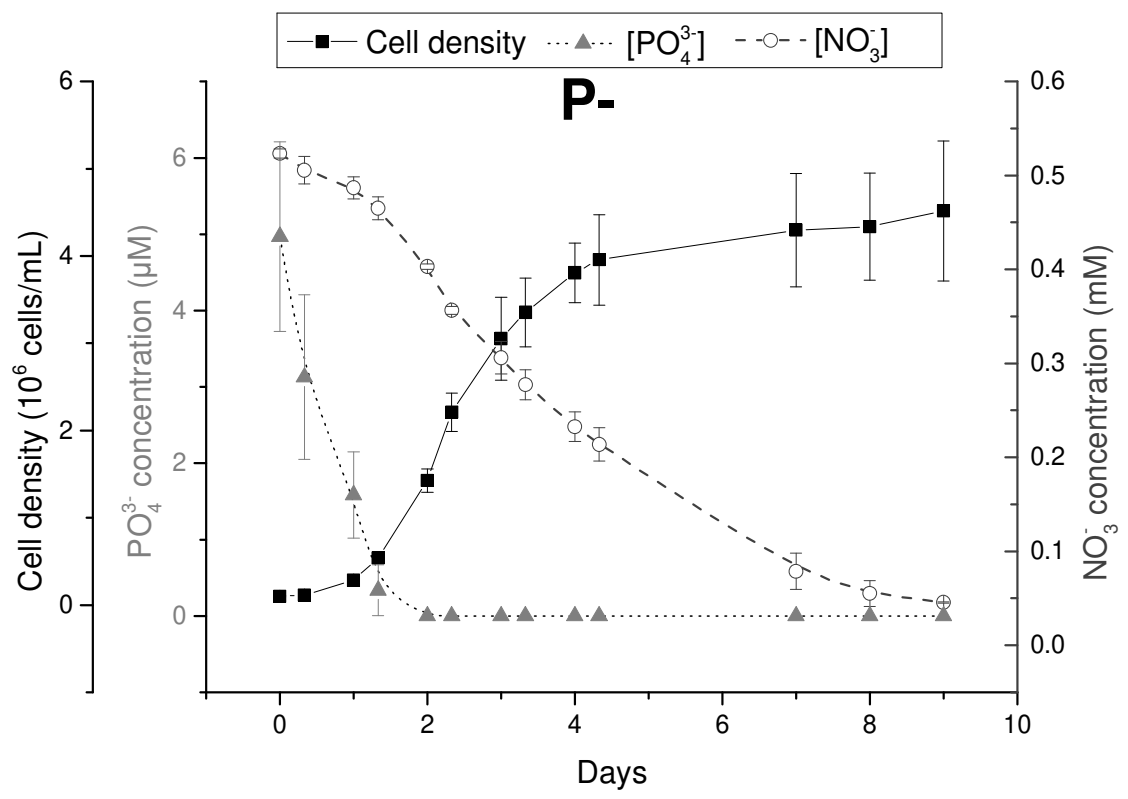

D

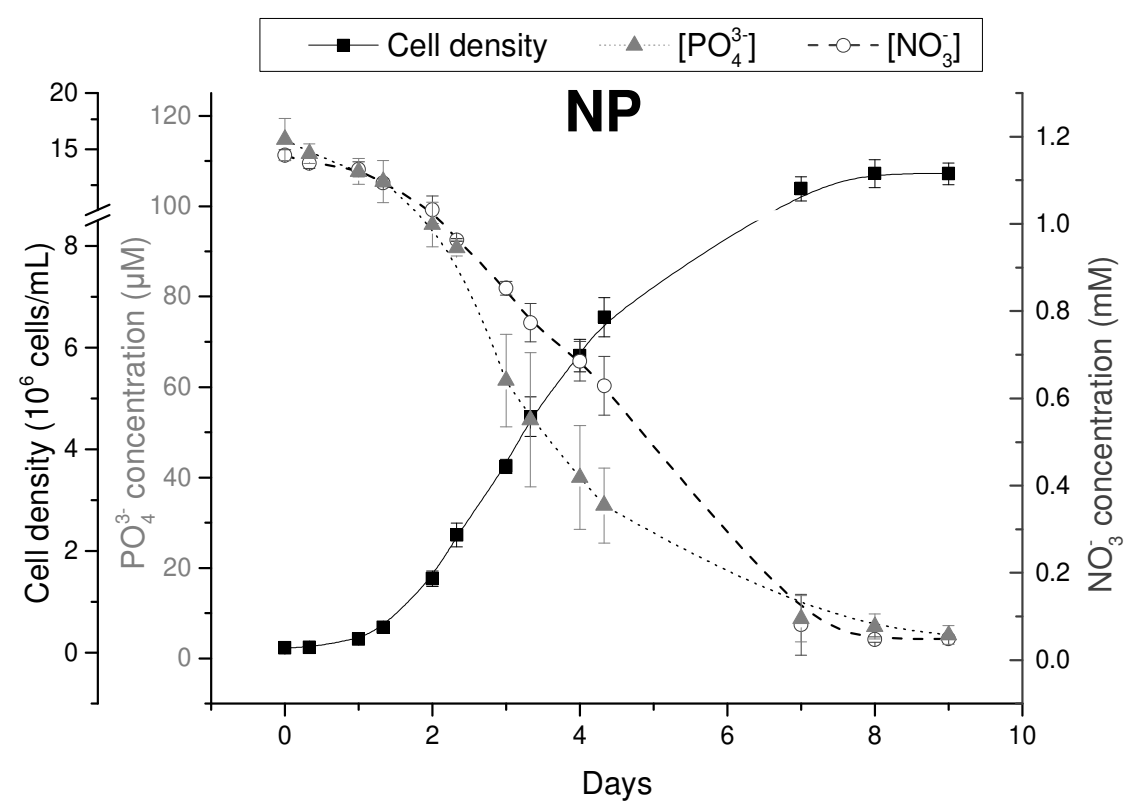


Fig. 1. Growth of T. lutea under control (NP), N-limited (N-) or P-limited (P-) conditions over 9 days in batch cultures. (Mean \pm S.D., $\mathrm{n}=5$ ). (A) Semi-log plot of growth curves (cell density $\mathrm{mL}^{-1}$ ) and specific growth rate $\left(\mathrm{d}^{-1}\right),(\mathrm{B})$ Dissolved $\mathrm{NO}_{3}{ }^{-}$concentration $(\mathrm{mM})$ and $\mathrm{PO}_{4}{ }^{3-}$ concentration $(\mu \mathrm{M})$ in $\mathrm{N}$-limited cultures, (C) Dissolved $\mathrm{NO}_{3}{ }^{-}$concentration $(\mathrm{mM})$ and $\mathrm{PO}_{4}{ }^{3-}$ concentration $(\mu \mathrm{M})$ in P-limited cultures, (D) Dissolved $\mathrm{NO}_{3}{ }^{-}$concentration $(\mathrm{mM})$ and $\mathrm{PO}_{4}{ }^{3-}$ concentration $(\mu \mathrm{M})$ in NP cultures. 


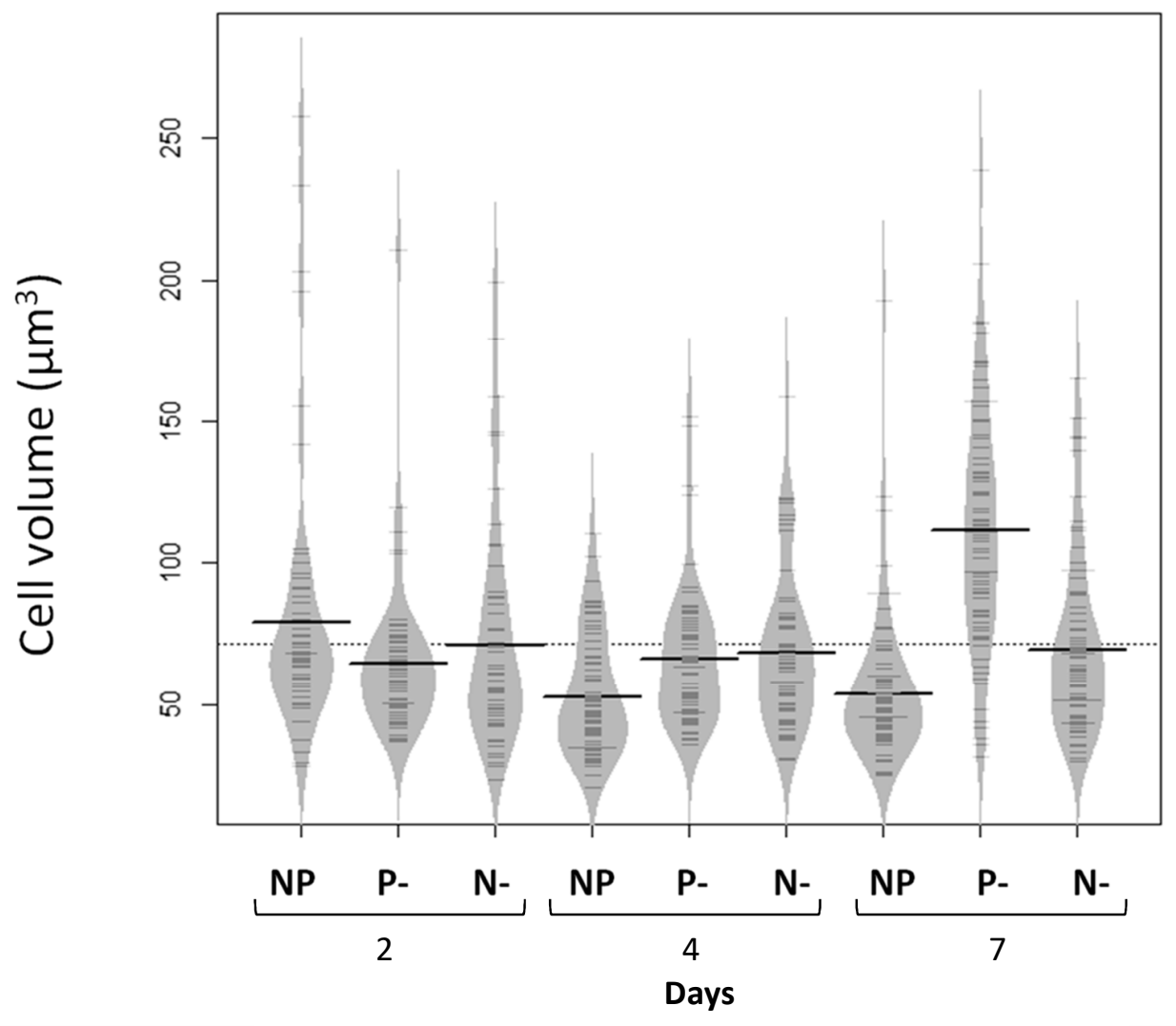

Fig. 2. Cell volume $\left(\mu \mathrm{m}^{3}\right)$ of $T$. lutea grown under control (NP), N-limited (N-) or P-limited (P-) conditions in batch cultures. The thickness of the spindle-shaped figures is correlated with the volume distribution of 60 to 80 cells. Horizontal black lines indicate average volumes. 
A

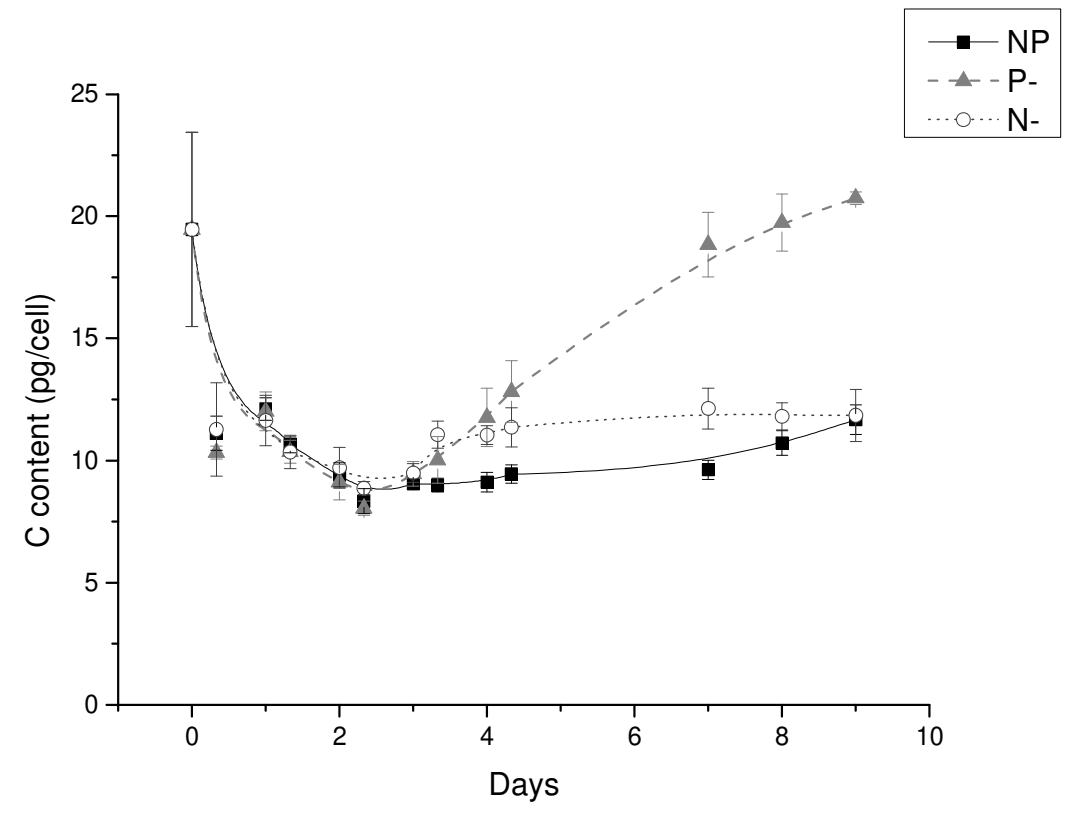

B

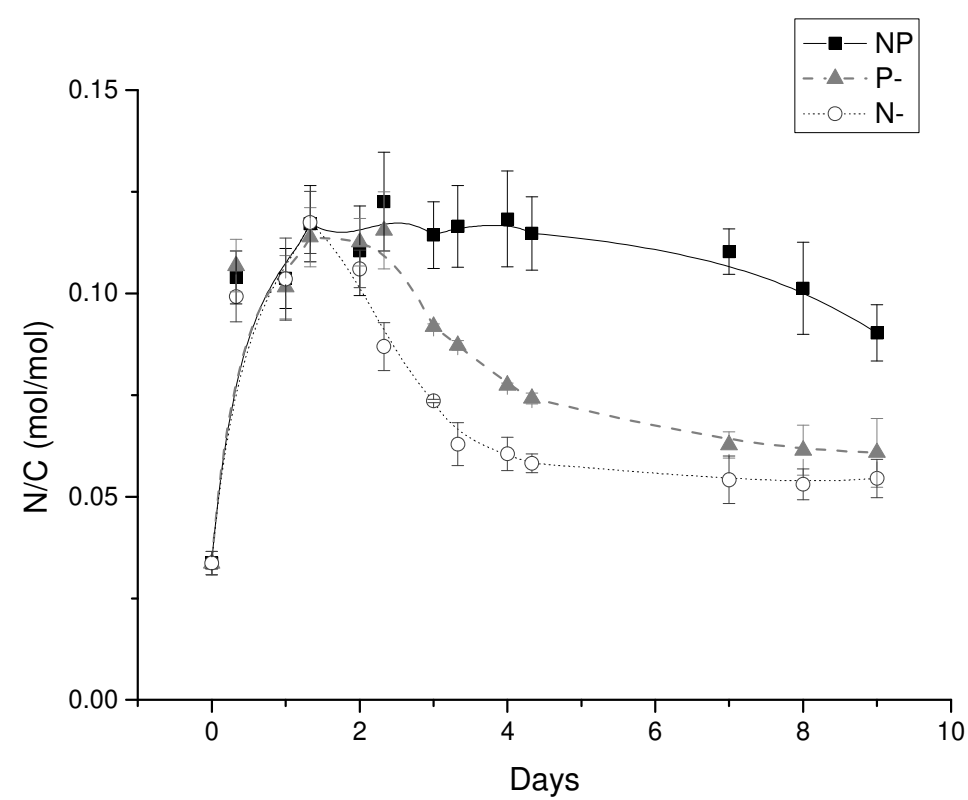




\section{C}

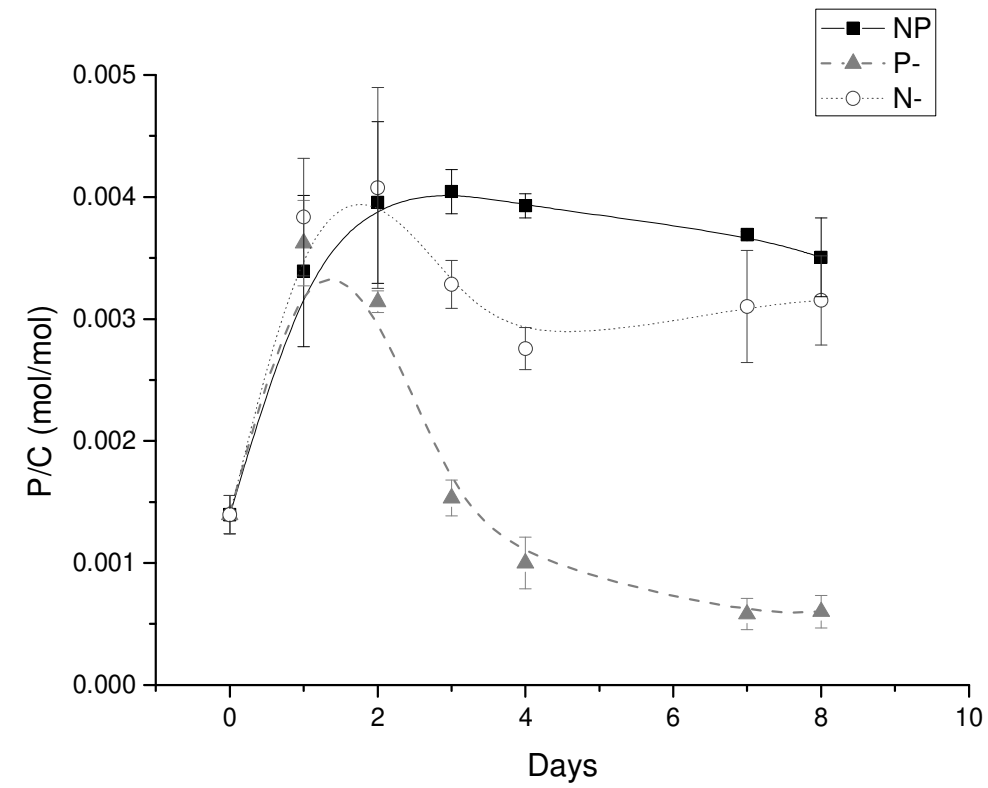

Fig. 3. Particulate carbon, nitrogen and phosphorus in $T$. lutea grown under control (NP), $\mathrm{N}$-limited (N-) or P-limited (P-) conditions over 9 days in batch cultures. (Mean \pm S.D., $\mathrm{n}=3$ ). (A) Carbon content per cell (pg cell $^{-1}$ ), (B) Nitrogen content per unit cell carbon ( $\left.\mathrm{mol} / \mathrm{mol}\right)$, (C) Phosphorus content per unit cell carbon $(\mathrm{mol} / \mathrm{mol})$. 
A

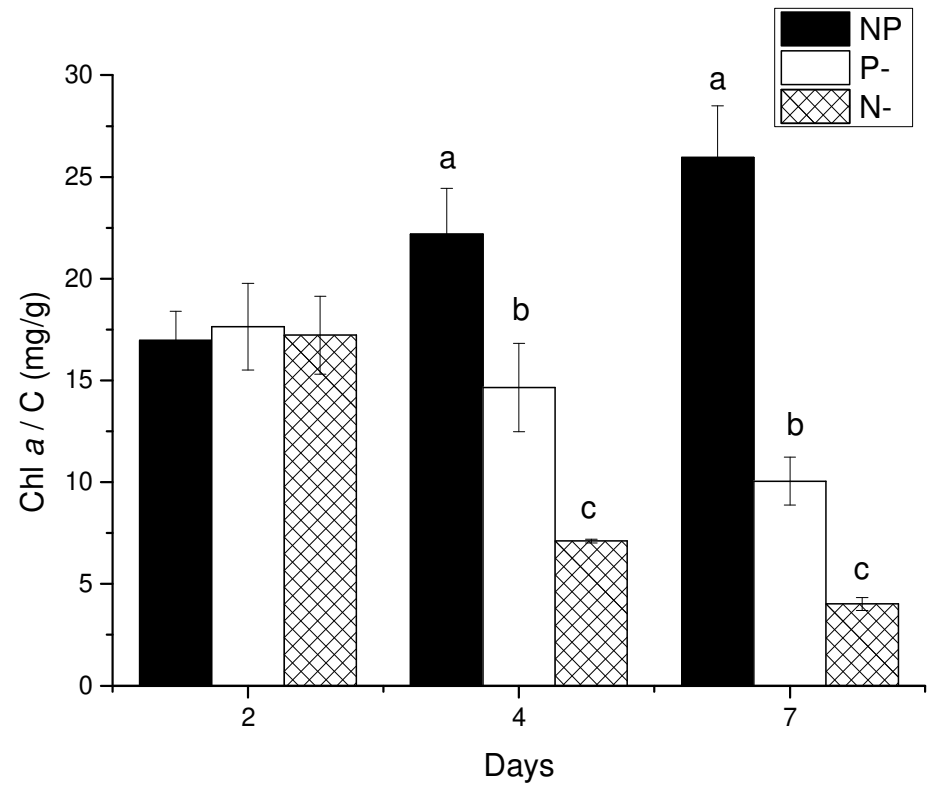

B

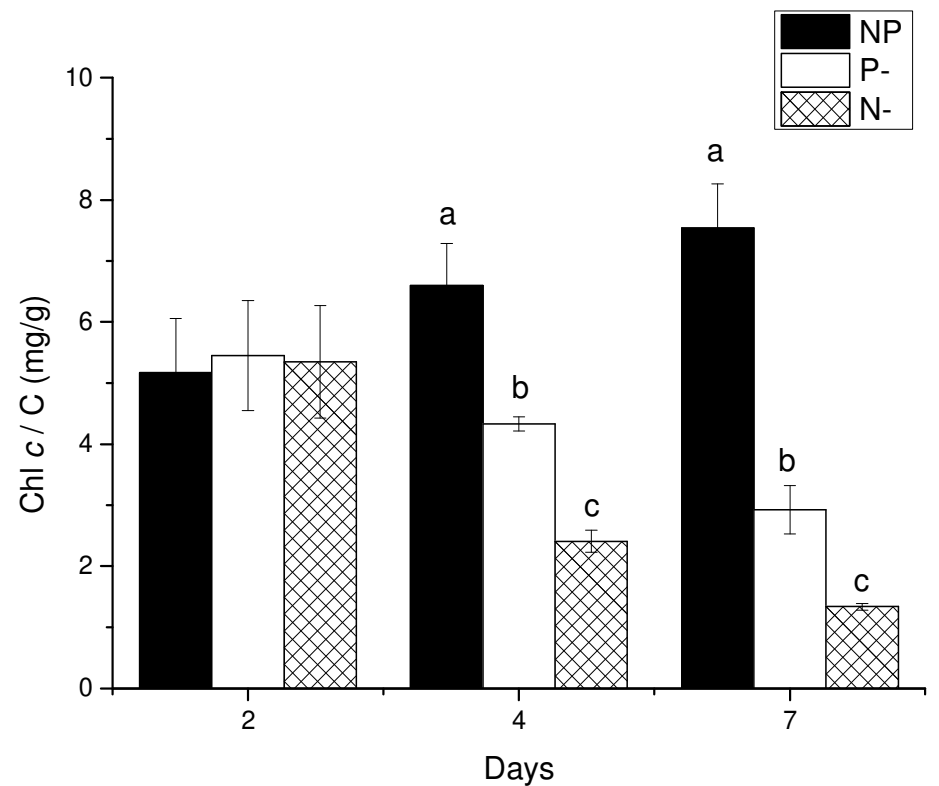




\section{C}

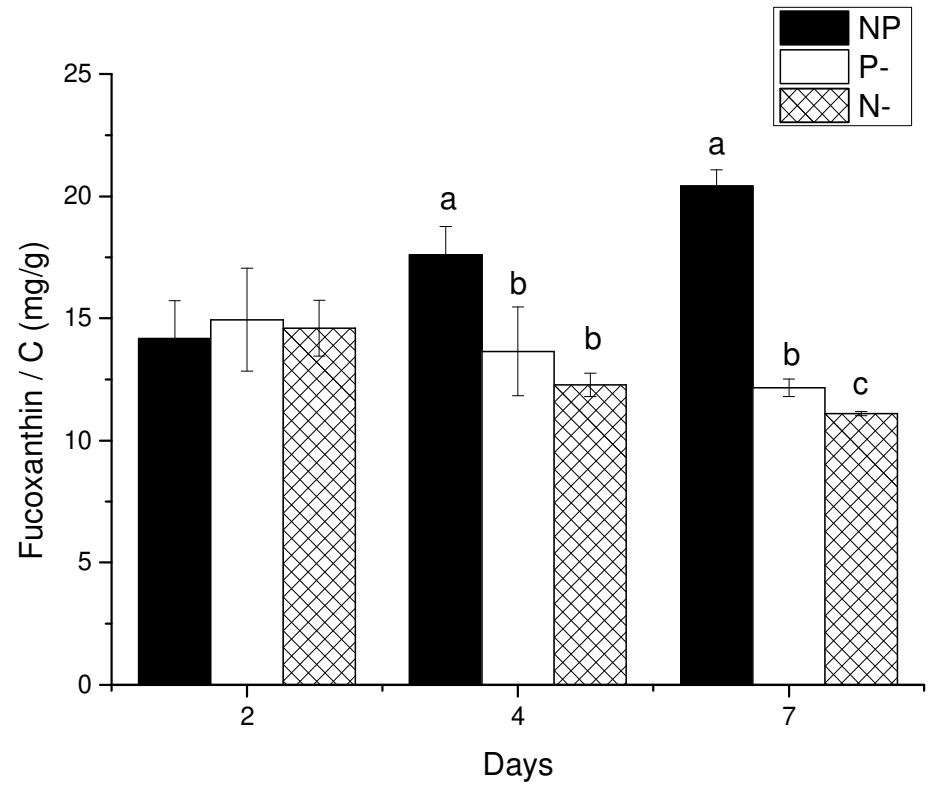

Fig. 4. Cellular pigment contents of T. lutea grown under control (NP), N-limited (N-) or P-limited (P-) conditions (Mean \pm S.D., $n=3$ ), different letters indicate significant $(\mathrm{p}<0.05)$ differences at each day of culture. (A) Chl $a$ content per unit cell carbon (mg/g), (B) Chl $c$ content per unit cell carbon (mg/g), (C) Fucoxanthin content per unit cell carbon $(\mathrm{mg} / \mathrm{g})$. 
A

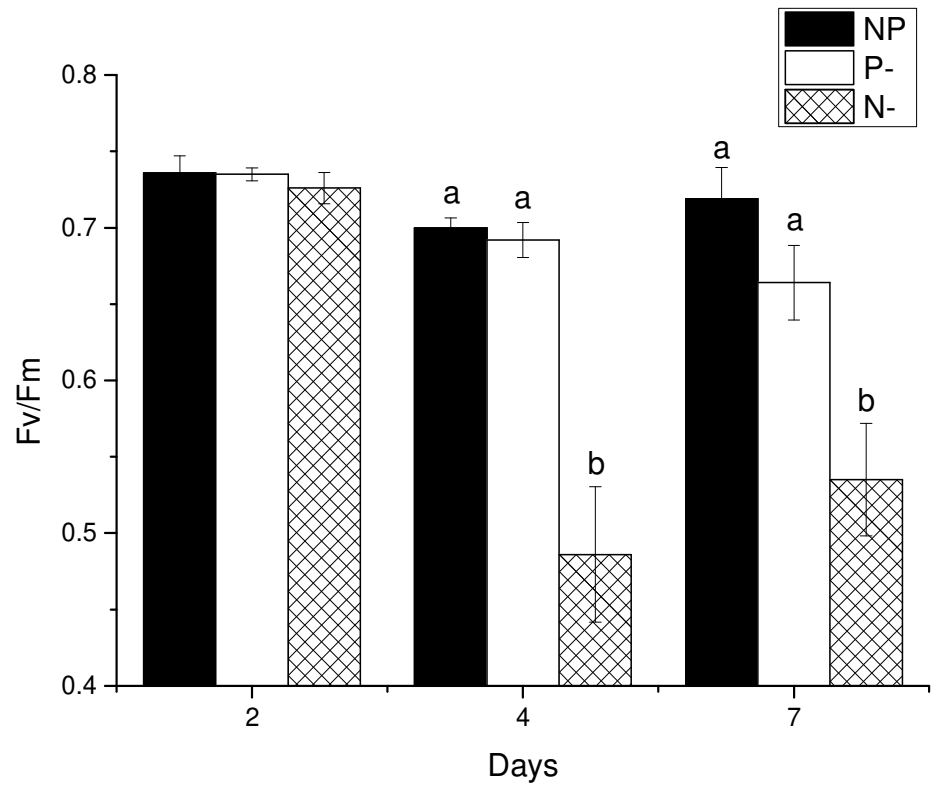

B

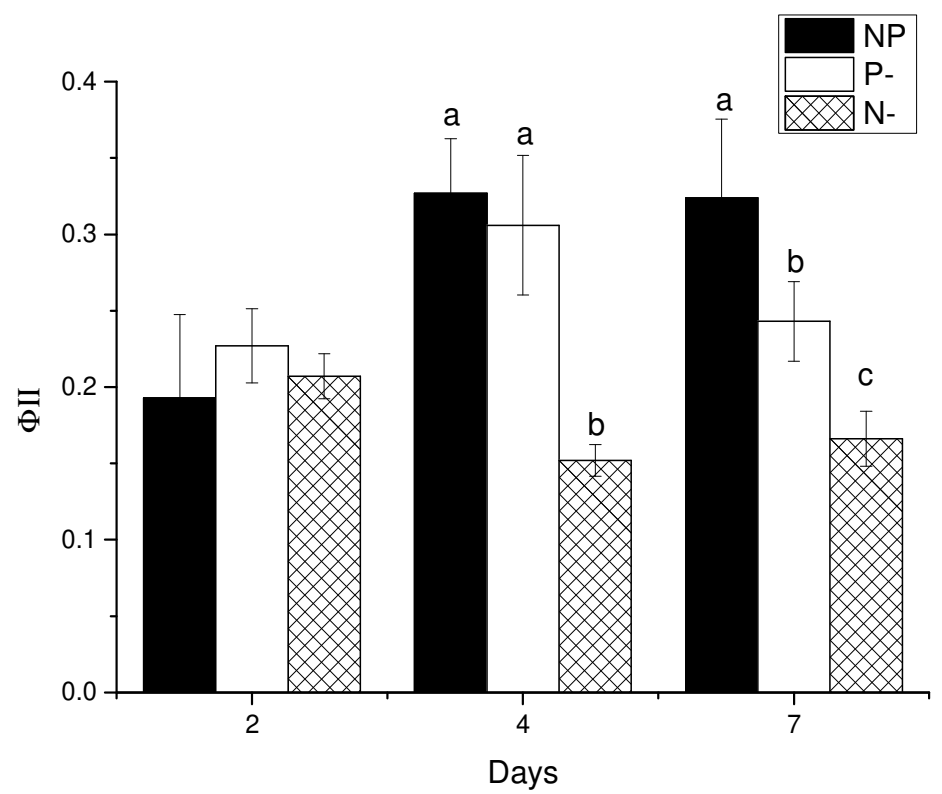


C

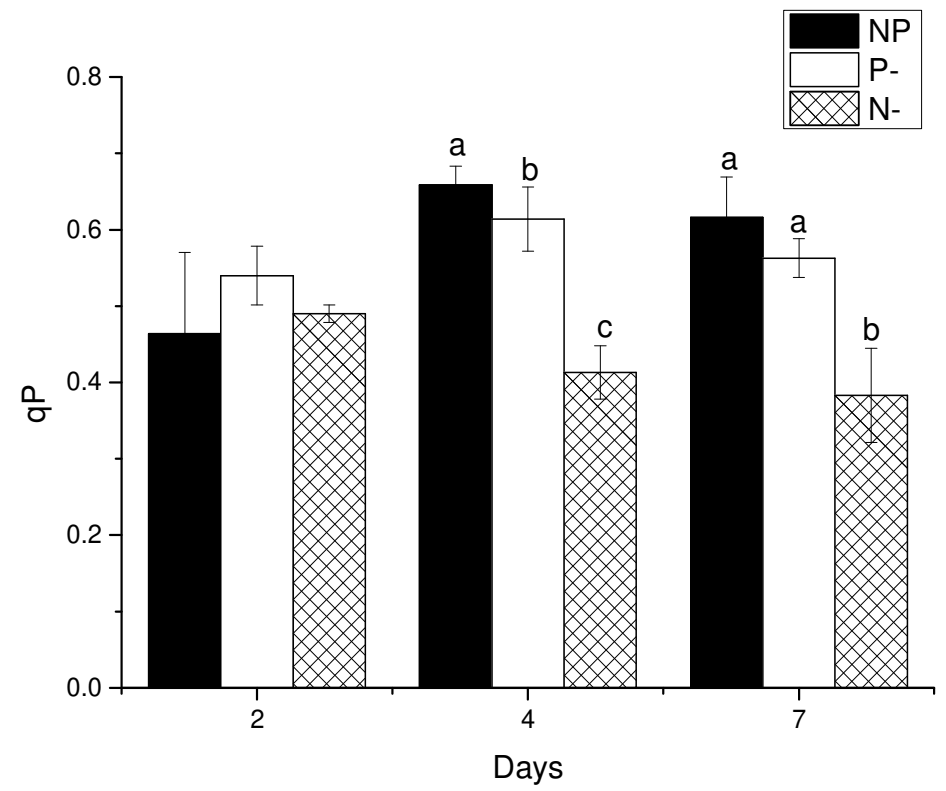

D

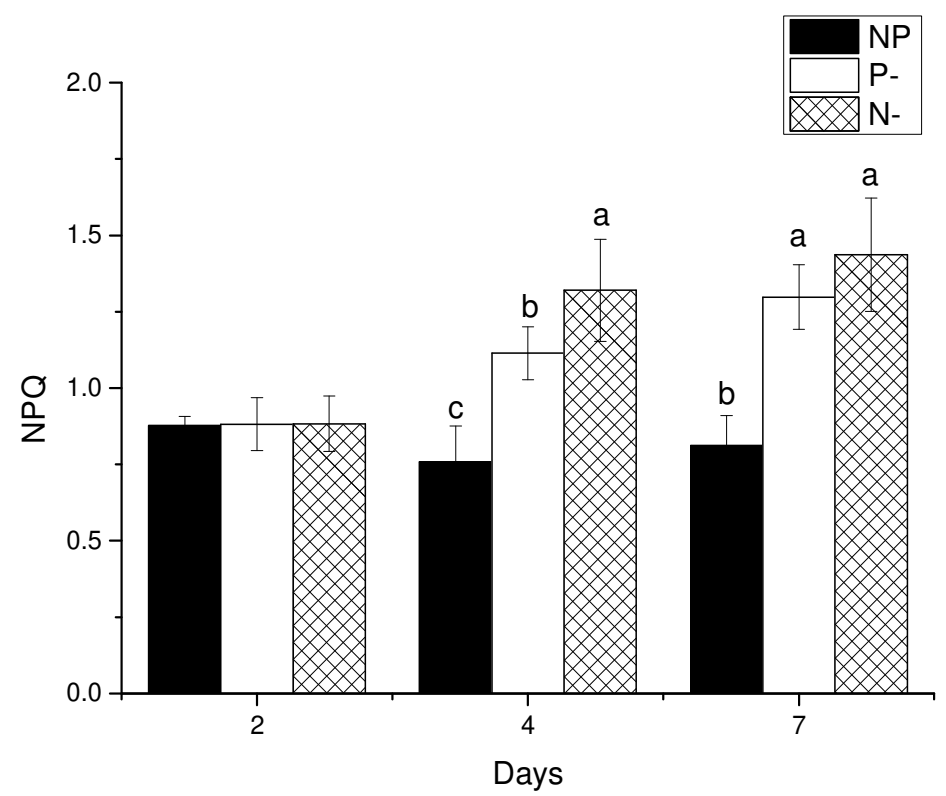




\section{E}

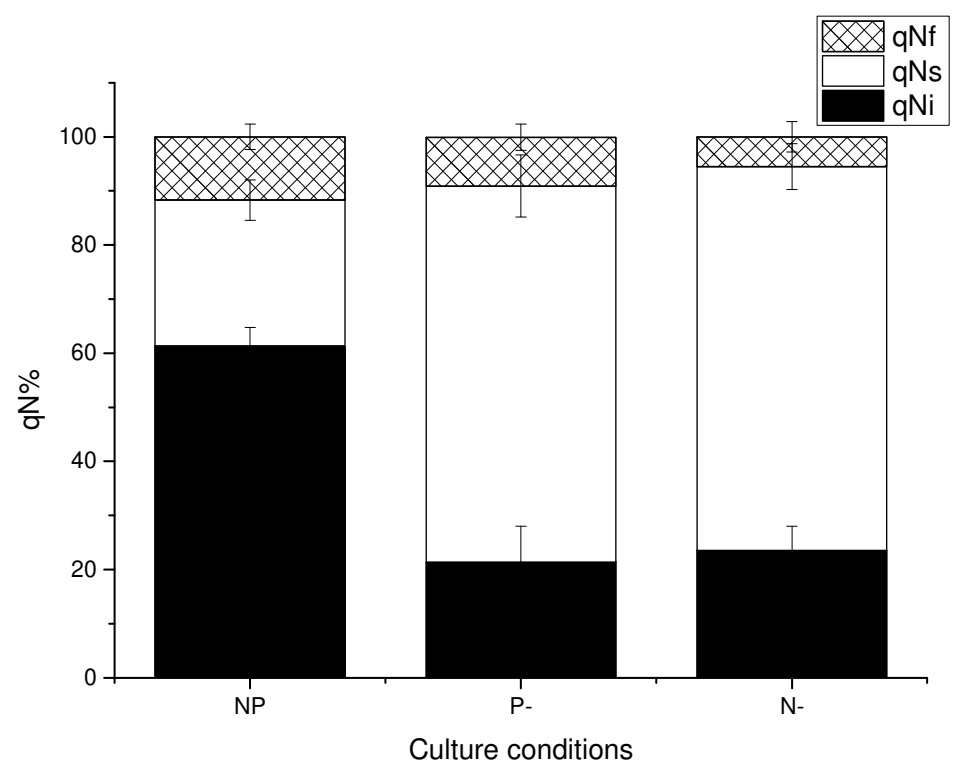

Fig. 5. Chlorophyll $a$ fluorescence parameters of T. lutea grown under control (NP), N-limited (N-) or Plimited $(\mathrm{P}-)$ conditions. Different letters indicate significant $(\mathrm{p}<0.05)$ differences at each day of culture (Mean \pm S.D., $n=3$ ). (A) Maximum photochemical efficiency of PSII $\left(F_{v} / F_{m}\right),(B)$ Effective photochemical efficiency of PSII ( $\left.\Phi_{\mathrm{II}}\right)$ under $300 \mu \mathrm{mol}$ photons $\mathrm{m}^{-2} \mathrm{~s}^{-1}$, (C) Photochemical quenching (qP) under $300 \mu \mathrm{mol}$ photons $\mathrm{m}^{-2} \mathrm{~s}^{-1}$, (D) Non-photochemical quenching (NPQ) under $300 \mu \mathrm{mol}$ photons $\mathrm{m}^{-2} \mathrm{~s}^{-1}$, (E) Proportions of $\mathrm{qN}_{\mathrm{f}}, \mathrm{qN}_{\mathrm{i}}$ and $\mathrm{qN}_{\mathrm{s}}$ in $\mathrm{qN}$ after a high irradiance $\left(1000 \mu \mathrm{mol}\right.$ photons $\left.\mathrm{m}^{-2} \mathrm{~s}^{-1}\right)$ in day- 4 cells. 
A

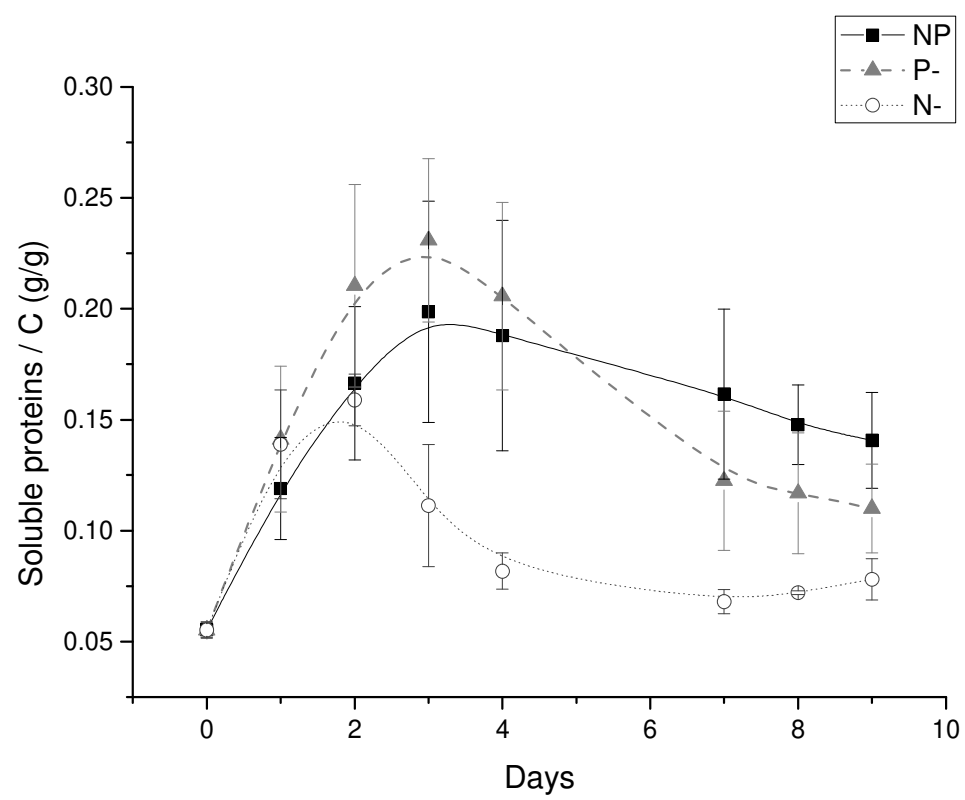

B

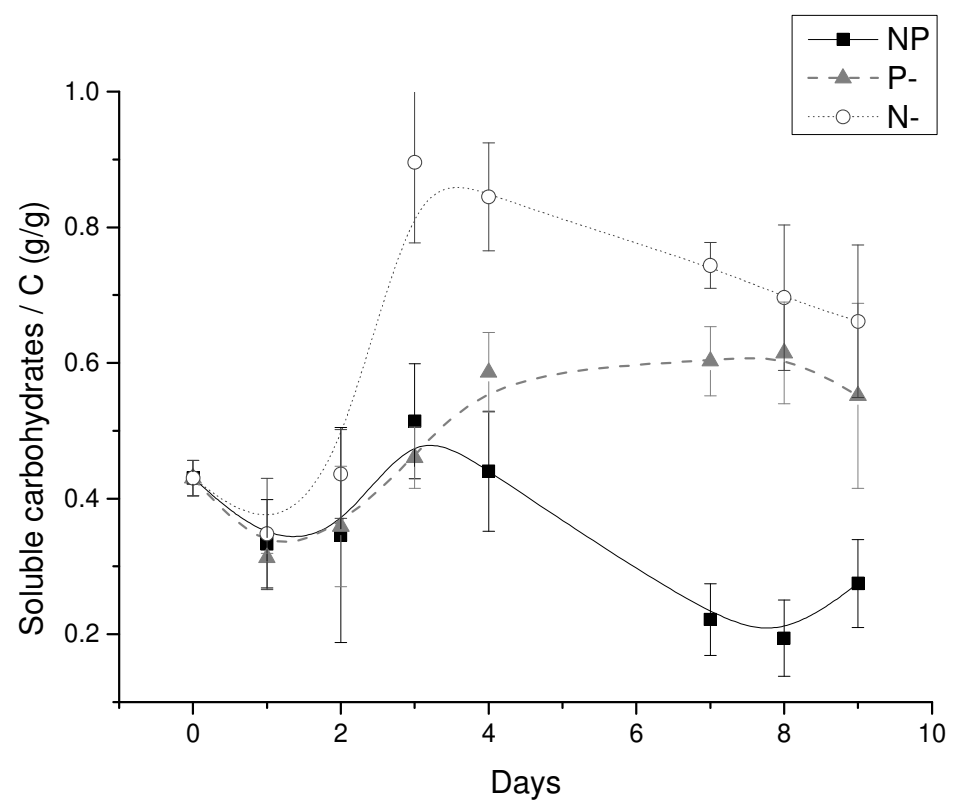


C

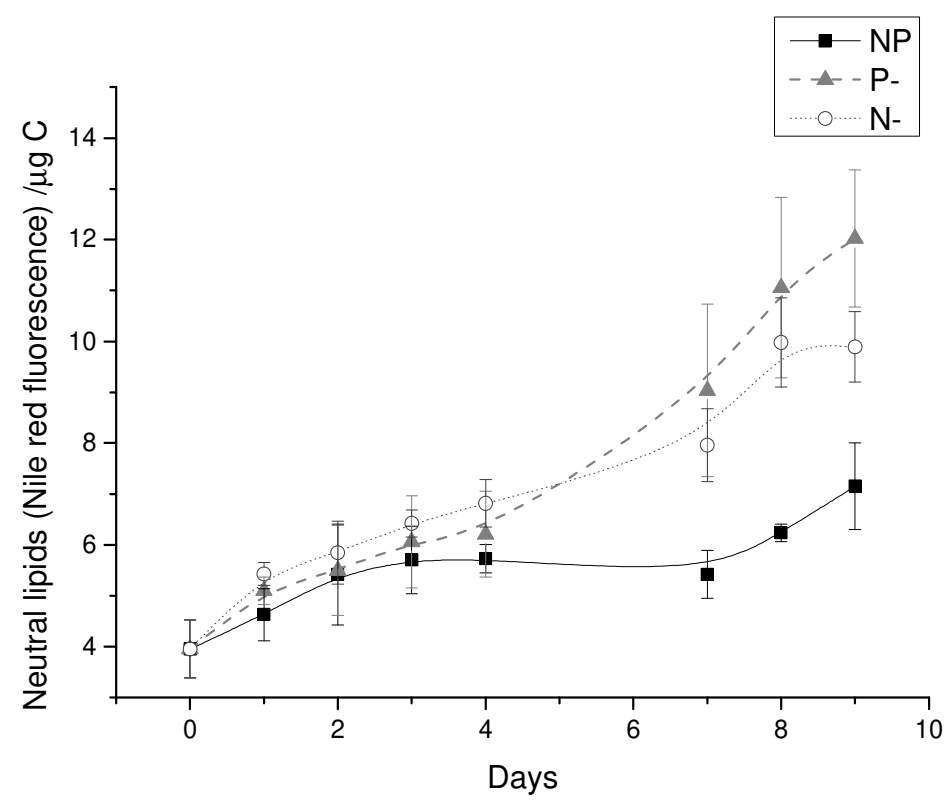

D

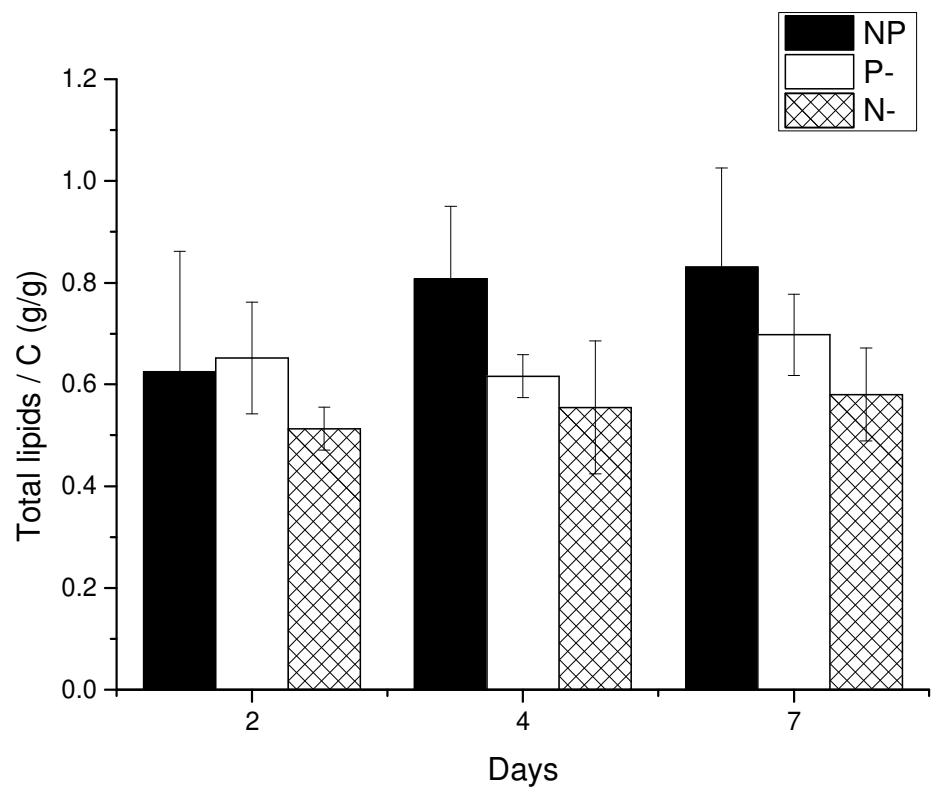


Fig. 6. Proximate biochemical composition of $T$. lutea grown under control (NP), N-limited (N-) or P-limited (P-) conditions over 9 days in batch cultures. (Mean \pm S.D., $n=3$ ). (A) Soluble protein content per unit cell carbon (g/g), (B) Soluble carbohydrate content per unit cell carbon (g/g), (C) Fluorescence of microalgal cells stained with Nile red per unit cell carbon $\left(\mu \mathrm{g} \mathrm{C}^{-1}\right)$ as measurements of neutral lipid content, (D) Total lipid content per unit cell carbon $(\mathrm{g} / \mathrm{g})$. 
A

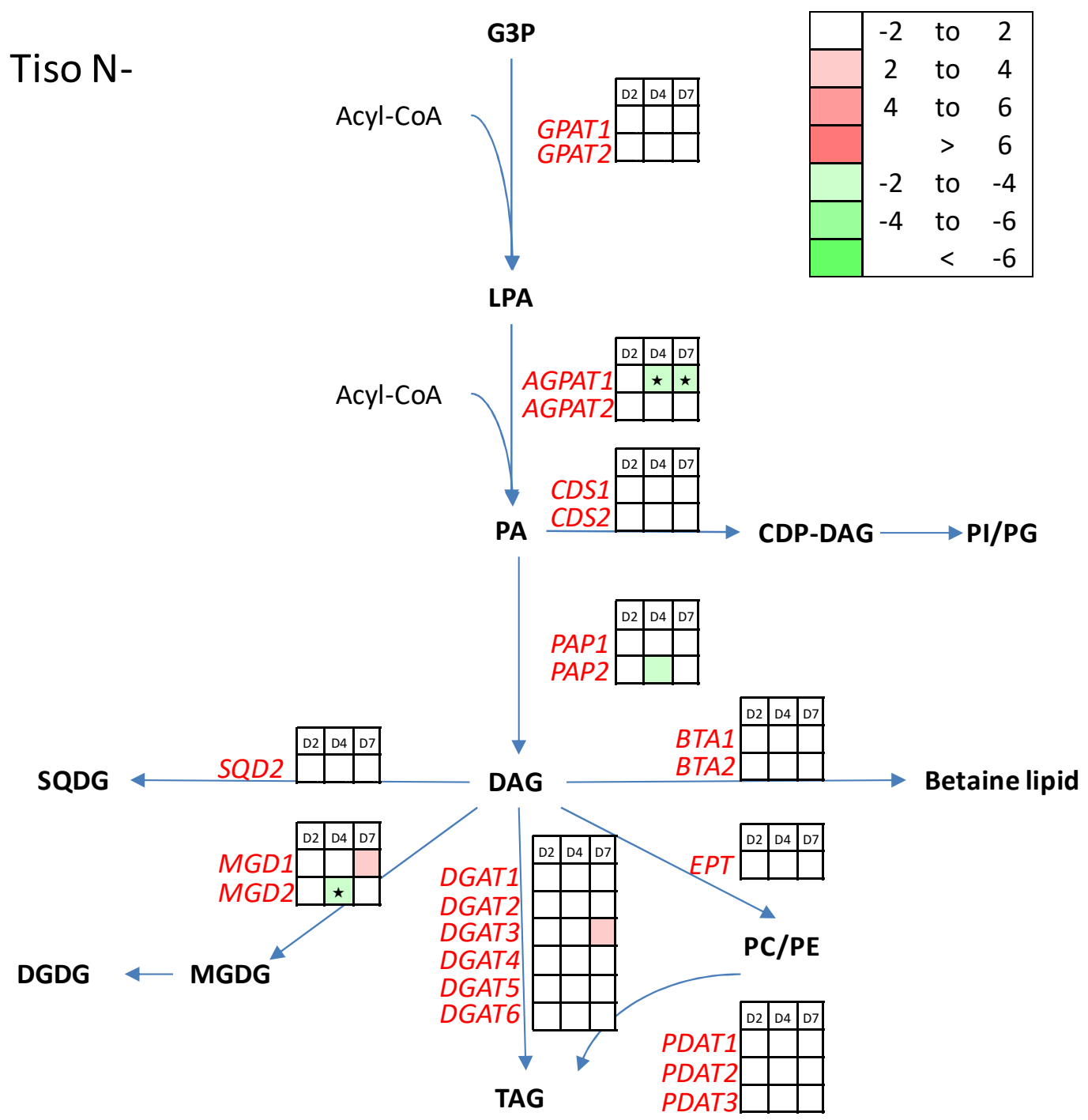




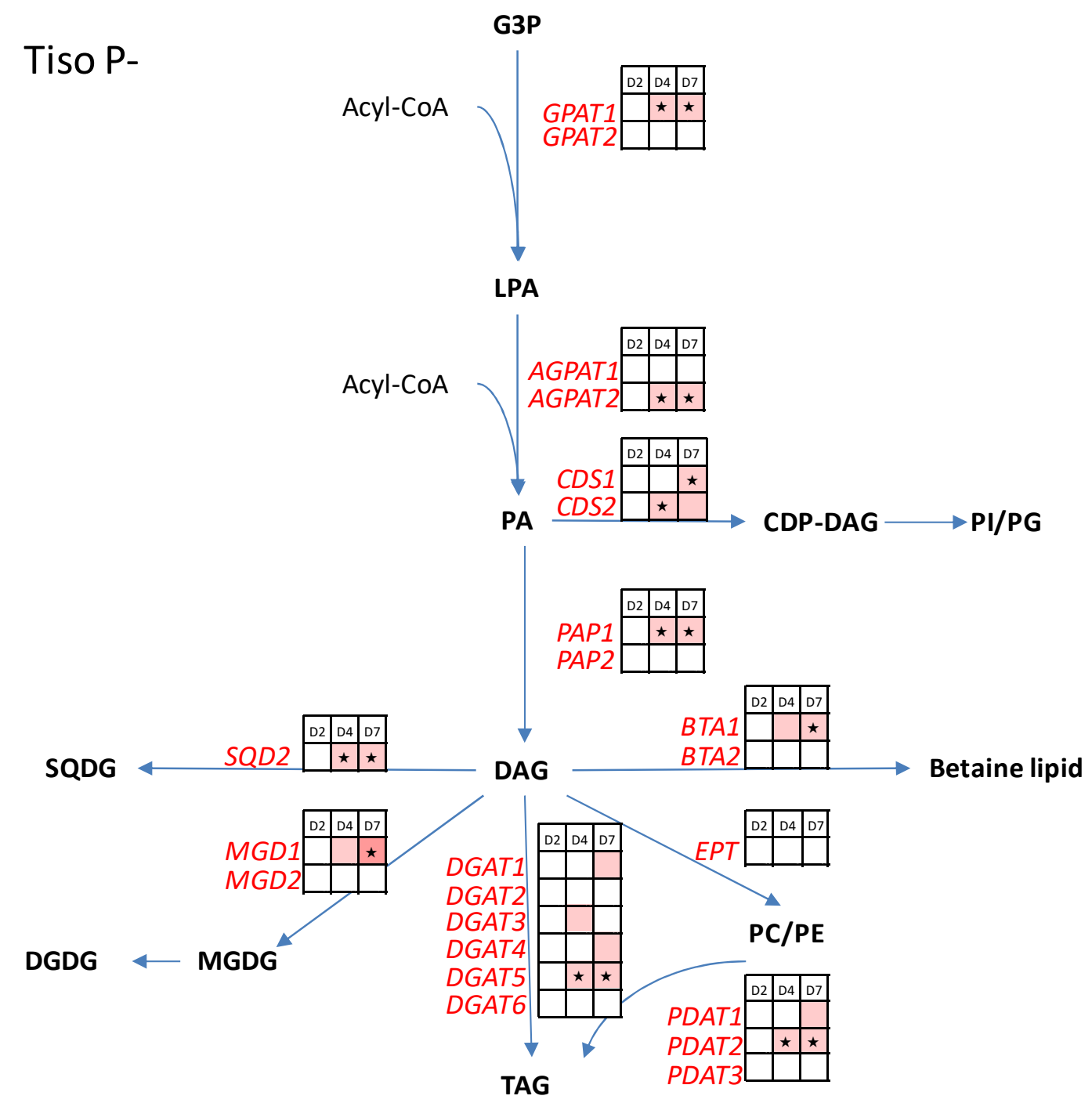

Fig. 7. Transcriptional fold changes of 23 genes/isogenes coding for 10 enzymes involved in TAG and membrane lipid biosynthetic pathways in T. lutea, from triplicate cultures under (A) N-limited (N-) or (B) Plimited (P-) conditions. Colored squares indicate the regulation pattern on day 2, day 4 and day 7 (red, upregulated; green, downregulated). For both treatments, day-2 NP cultures were used as calibrator. Asterisks indicate significant regulation compared with day-2 NP cultures $\left(\mathrm{p}<0.01\right.$ and $\left[\log _{2}\right.$ fold $>1$ or $\log _{2}$ fold $\left.<-1\right]$ or $\mathrm{p}<0.05$ and $\left[\log _{2}\right.$ fold $>2$ or $\log _{2}$ fold $\left.<-2\right]$ ). See Table $\mathrm{S} 1$ for correspondence between gene abbreviations 
and protein ID. Compounds: CDP-DAG, cytidine diphosphate diacylglycerol; DAG, diacylglycerol; DGDG, digalactosyldiacylglycerol; G3P, glycerol-3-phosphate; LPA, lysophosphatidic acid; MGDG, monogalactosyldiacylglycerol; PA, phosphatidic acid; PC, phosphatidylcholine; PE, phosphatidylethanolamine; PG, phosphatidylglycerol; PI, phosphatidylinositol; SQDG, sulfoquinovosyldiacylglycerol; TAG, triacylglycerol. 
A

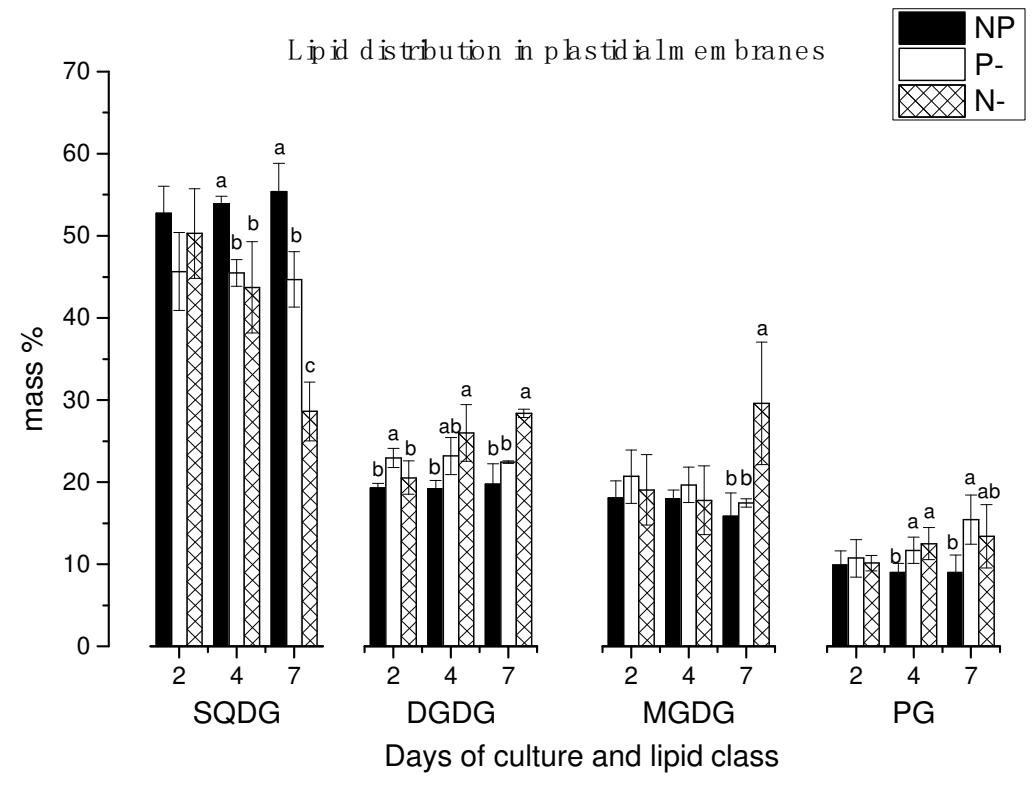

B

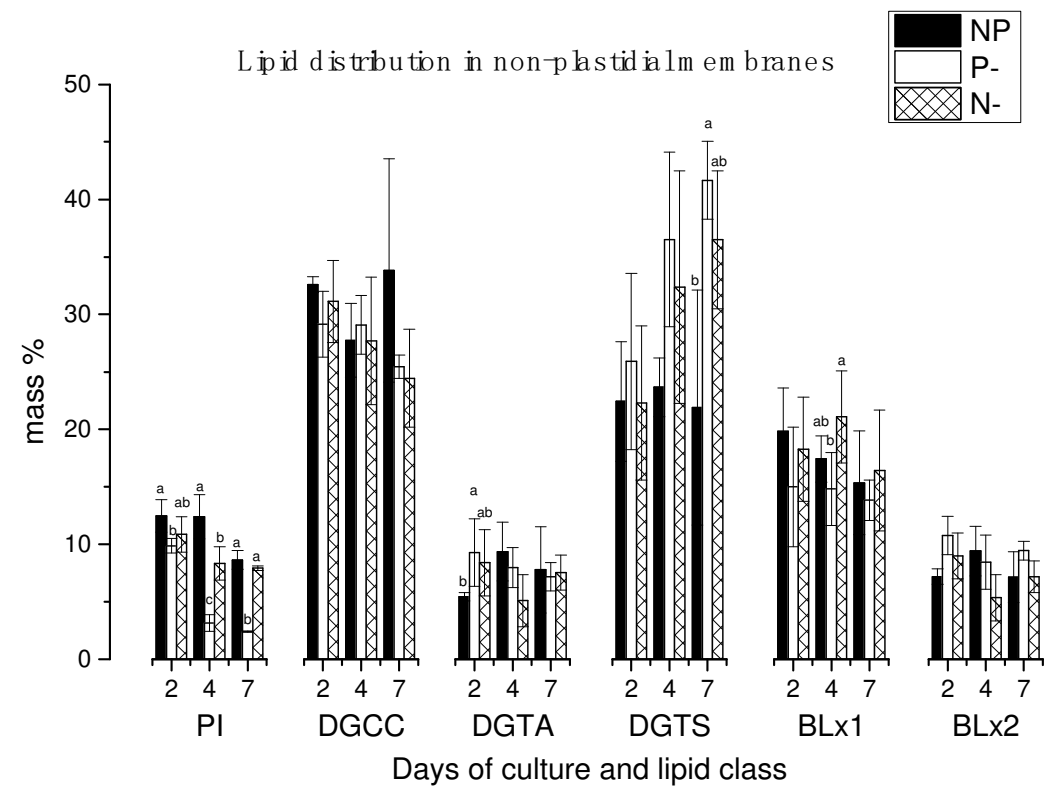

Fig. 8. Lipid composition (expressed in mass \%) of T. lutea grown under control (NP), N-limited (N-) or Plimited (P-) conditions. Different letters indicate significant $(\mathrm{p}<0.05)$ differences at each day of culture 
(Mean \pm S.D., $n=3$ ). (A) Lipid composition in plastidial membranes (SQDG, sulfoquinovosyl-diacylglycerol; DGDG, digalactosyldiacylglycerol; MGDG, monogalactosyldiacylglycerol; PG, phosphatidylglycerol); (B) Lipid composition in non-plastidial membranes (PI, phosphatidylinositol; DGCC, diacylglycerol-3carboxymethylcholine; DGTA, diacylglycerylhydroxymethyltrimethyl- $\beta$-alanine; $\quad$ DGTS, diacylglyceroltrimethylhomoserine; BLx1 and BLx2, two putative betaine lipids). 
A

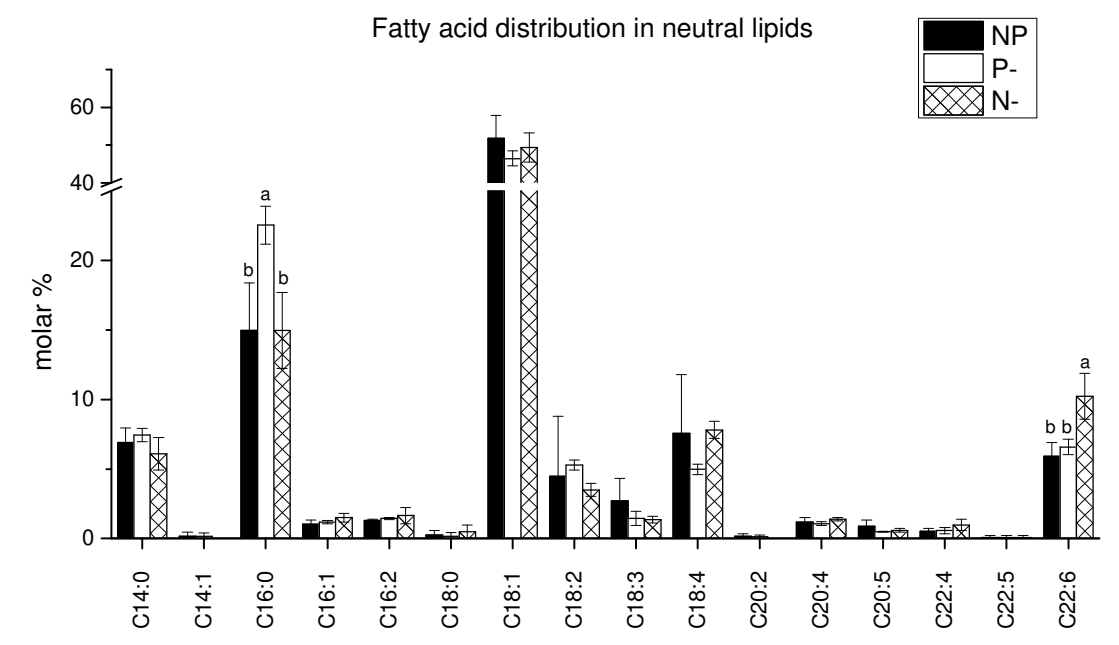

Fatty acid composition

B

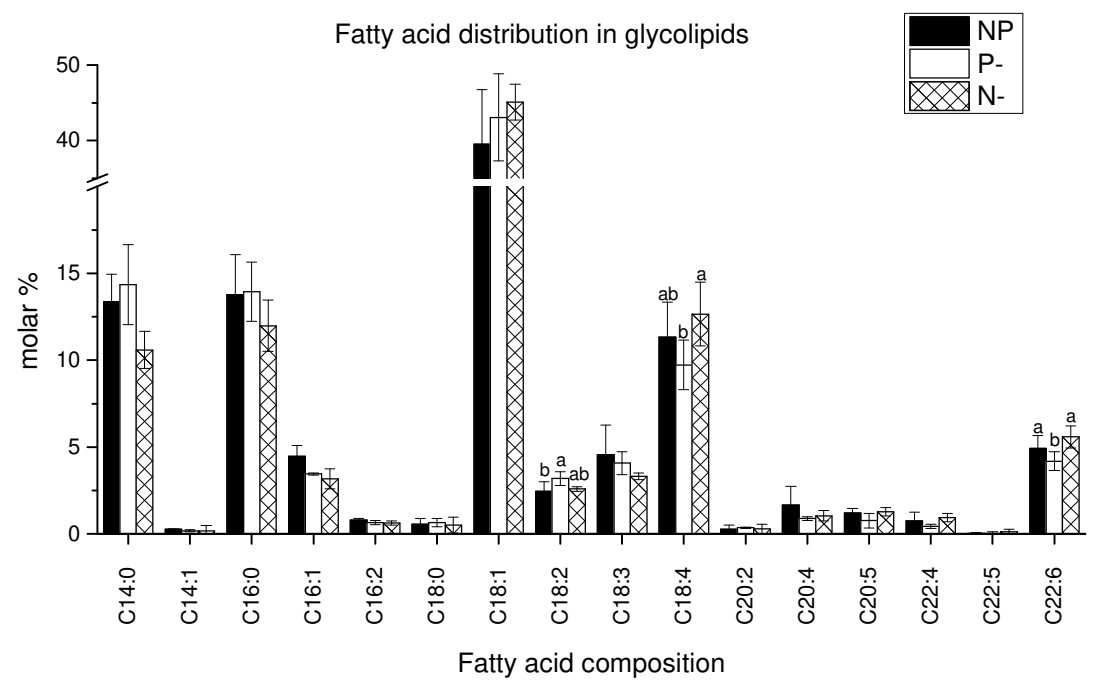




\section{C}

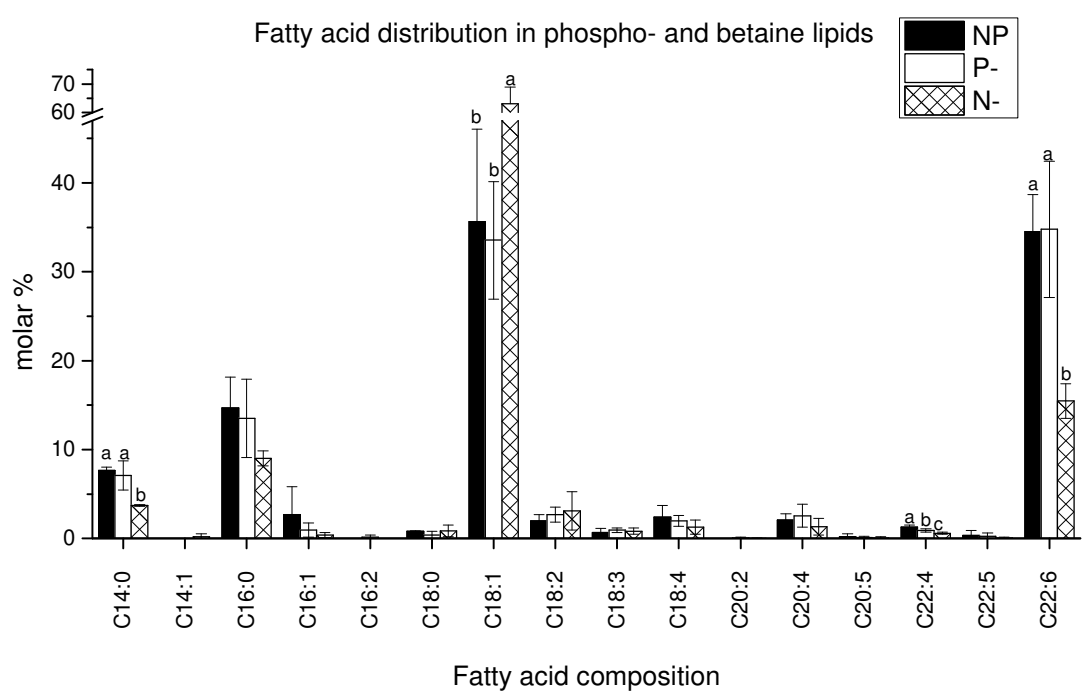

Fig. 9. Fatty acid composition (expressed in mol \%) in three main fractions of lipids extracted from T. lutea grown under control (NP), N-limited (N-) or P-limited (P-) conditions on day 4. Different letters indicate significant $(\mathrm{p}<0.05)$ differences (Mean \pm S.D., $n=3)$. (A). Fatty acid composition in neutral lipids, (B). Fatty acid composition in glycolipids, (C). Fatty acid composition in phospho- and betaine lipids. Fatty acids: C14:0, myristic acid; C14:1n-5, myristoleic acid; C16:0, palmitic acid; C16:1n-7, palmitoleic acid; C16:2n-6, hexadecadienoic acid; C18:0, stearic acid; C18:1n-9, oleic acid; C18:2n-6, linoleic acid; C18:3n-3, $\alpha$-linolenic acid; C18:4n-3, stearidonic acid; C20:2n-6, eicosadienoic acid; C20:4n-6, arachidonic acid; C20:5n-3, eicosapentaenoic acid; C22:4n-6, docosatetraenoic acid; C22:5n-3, docosapentaenoic acid; C22:6n-3, docosahexaenoic acid. 
Supplementary Table. S1. List of enzymes and related genes analyzed by real-time qPCR and their respective primers

\begin{tabular}{|c|c|c|c|c|}
\hline Enzyme & $\begin{array}{c}\text { Gene } \\
\text { abbreviation }\end{array}$ & Protein ID & Primer-F(5'-3') & Primer-R(5'-3') \\
\hline \multirow[t]{2}{*}{ Glycerol-3-phosphate acyl transferase } & GPAT1 & Tisochrysis_lutea_Proteine_11885 & GCCAAAAGCCGCCCTAA & CGAACCTCAATCCCGAGTATG \\
\hline & GPAT2 & Tisochrysis_lutea_Proteine_02054 & CGAGAGATTGGAGCCAGGAA & TCCCCATCATCACGAGCAG \\
\hline \multirow[t]{2}{*}{ Lyso-phosphatidic acid acyl transferase } & AGPAT1 & P2632.01 & ACAGTGCGGCAGTAAGGACG & CAGGACAAACCCAGTGAGCC \\
\hline & AGPAT2 & Tisochrysis_lutea_Proteine_18153 & CCATCGCCGTCTTGCTTACT & TCAACGACGCTCCAACACAC \\
\hline \multirow[t]{2}{*}{ Phosphatidic acid phosphatase } & PAP1 & Tisochrysis_lutea_Proteine_01516 & GCAAGTCGCAAGCAAATCAA & CCACAAAGGCAGTCTCAAATCC \\
\hline & PAP2 & Tisochrysis_lutea_Proteine_12061 & GCCTGAGTCTGGTTGTTGTCG & GTGTTGGAGCTGGGTGGTTC \\
\hline \multirow[t]{6}{*}{ Diacylglycerol acyltransferase } & DGAT1 & Tisochrysis_lutea_Proteine_5058 & CCGTATCCCAGCGTTCATTT & GCATATTGTACTGTCTCCCATCCC \\
\hline & DGAT2 & Tisochrysis_lutea_Proteine_11098 & CACTTTCGTCTGCTCGCTCTAC & GTGCCCGCAACAGGTCTT \\
\hline & DGAT3 & Tisochrysis_lutea_Proteine_22106 & TCGCACATCTAAAACACTACTCGG & GGGAACGGCAAGCCAAAC \\
\hline & DGAT4 & Tisochrysis_lutea_Proteine_6172 & ATCGTTTGTGGGGTTTGGG & TTTGGTCTTCCTTGGCTCGTA \\
\hline & DGAT5 & Tisochrysis_lutea_Proteine_15851 & GGGGATGAGATGCGACGAC & AGCGAAGGATGCCTGGGT \\
\hline & DGAT6 & Tisochrysis_lutea_Proteine_01740 & GGCCGGGTTCTACGTTTTCT & GCATTCCACCACGCTTTGT \\
\hline \multirow[t]{3}{*}{ Phospholipid:diacylglycerol acyltransferase } & PDAT1 & P2565.01 & CCTGGCTGTCCTCACTATTCG & GCCGCTTCCGCATTTTC \\
\hline & PDAT2 & Tisochrysis_lutea_Proteine_7980 & TCAGCCGATTAAGGCATAGGAA & CGGATAAAGCGAGTGCAACAG \\
\hline & PDAT3 & Tisochrysis_lutea_Proteine_9543 & CAACGCATACTCCTGAAGAAACC & TGTGCCCTTGCTGAAAACCT \\
\hline \multirow[t]{2}{*}{ MGDG synthase } & MGD1 & Tisochrysis_lutea_Proteine_11866 & GAGACGGGAAATGTCAAGCAC & GGGTCATCGAGCCAAGCA \\
\hline & MGD2 & Tisochrysis_lutea_Proteine_8147 & TAGGAGTAGGCAGGACACGAGG & CAAGCGTCAATCAATAGAAATCAAG \\
\hline SQDG synthase & SQD2 & P3963.01 & AGGCGGCACCAGCACA & TCACCTTTTCAGACTCCACTCG \\
\hline Diacylglycerol ethanolaminephosphotransferase & EPT & Tisochrysis_lutea_Proteine_16476 & GGGGAGTATAGATGTTTAGAGGGACC & AATGGCACAGGAACGACGAG \\
\hline
\end{tabular}


Phosphatidate cytidylyltransferase

Betaine lipid synthase
CDS1

CDS2

BTA1

BTA2
Tisochrysis_lutea_Proteine_ 9387

Tisochrysis_lutea_Proteine_3348

Tisochrysis_lutea_Proteine_17669

Tisochrysis_lutea_Proteine_31533
CCGATTCATTCCAACGACG

СТСТTCCTTGTTTCCTTCCTTCTO

GGAATGGACGAAAGAGGTGTTG

ATGCGGGCGAAGGACA
ACAAGCGATGCGAAACTGC

TTCACCCGACATTCCTCCAC

TGTTGCGGGAGTGAATGTGA

CAGGCTGACGGCTACGATG 